Illinois State University

ISU ReD: Research and eData

Theses and Dissertations

$4-18-2018$

\title{
Time Does Not Heal All Wounds: Temporal Differences In Spinal Pathology Among Pre-Columbian Sites In West-Central Illinois
}

Abigail Peeples

Illinois State University, appeepl@ilstu.edu

Follow this and additional works at: https://ir.library.illinoisstate.edu/etd

Part of the History of Art, Architecture, and Archaeology Commons

\section{Recommended Citation}

Peeples, Abigail, "Time Does Not Heal All Wounds: Temporal Differences In Spinal Pathology Among PreColumbian Sites In West-Central Illinois" (2018). Theses and Dissertations. 983.

https://ir.library.illinoisstate.edu/etd/983

This Thesis is brought to you for free and open access by ISU ReD: Research and eData. It has been accepted for inclusion in Theses and Dissertations by an authorized administrator of ISU ReD: Research and eData. For more information, please contact ISUReD@ilstu.edu. 


\title{
TIME DOES NOT HEAL ALL WOUNDS: TEMPORAL DIFFERENCES IN SPINAL PATHOLOGY AMONG PRE-COLUMBIAN SITES \\ IN WEST-CENTRAL ILLINOIS
}

\begin{abstract}
Abigail Peeples
68 Pages

This research sought to examine a co-occurrence of three spinal pathologies, Schmorl's nodes, osteophytosis, and osteoarthritis, within three temporally sequential pre-Columbian sites in west-central Illinois. Middle Woodland period Albany Mounds (200 BCE - CE 400), Late Woodland period Kuhlman Mounds (CE 600 - 900) and Mississippian period Dickson Mounds (CE 900 - 1300), acted as proxies for their respective time periods in order to determine if there were any patterns among the three spinal pathologies present. Individuals with vertebrae were examined by joints and were scored based on discrete criteria for each pathology. Overall, highest frequency of individuals affected by Schmorl's nodes, osteophytosis, and osteoarthritis were located in the Dickson Mounds sample, providing evidence of a possible increase in mechanical stress and workload during the Mississippian Period. Highest frequency of Schmorl's nodes overall were observed equally within Kuhlman and Dickson Mounds, while osteophytosis was observed most frequently in Kuhlman and osteoarthritis was observed most frequently within Albany. There were no joints with all three pathologies coinciding. Four individuals had all three pathologies present in one joint within the spine, but never co-occurring. There were however, thirteen individuals with a co-occurrence of two pathologies, the majority possessing Schmorl's nodes and osteophytosis. Young Adults with Schmorl's nodes in Dickson Mounds
\end{abstract}


were found to be significantly more frequent than Young Adults in the other sites. Future research should include larger sample sizes and more consistent category sizes within the samples in order to limit gaps in data as well as skewed statistics due to small sample sizes.

KEYWORDS: West-central Illinois; Osteoarthritis; Osteophytosis; Schmorl's nodes; Vertebral pathology 
TIME DOES NOT HEAL ALL WOUNDS: TEMPORAL DIFFERENCES IN SPINAL PATHOLOGY AMONG PRE-COLUMBIAN SITES

IN WEST-CENTRAL ILLINOIS

ABIGAIL PEEPLES

A Thesis Submitted in Partial

Fulfillment of the Requirements for the Degree of

MASTER OF SCIENCE

Department Sociology and Anthropology

ILLINOIS STATE UNIVERSITY

2018 
Copyright 2018 Abigail Peeples 
TIME DOES NOT HEAL ALL WOUNDS: TEMPORAL DIFFERENCES IN SPINAL PATHOLOGY AMONG PRE-COLUMBIAN SITES

IN WEST-CENTRAL ILLINOIS

ABIGAIL PEEPLES

COMMITTEE MEMBERS:

Maria O. Smith, Chair

Abigail C. Stone 


\section{ACKNOWLEDGMENTS}

I would like to thank the Sociology and Anthropology department of Illinois State University for providing me with the means to further my academic career and succeed in the completion of this thesis. Special thanks goes to my advisor, Dr. Maria O. Smith for mentoring me through these two year of research and writing. If it were not for her own drive and talent in the Bioarchaeological field to inspire me, I would not have come so far. I would also like to thank Dr. Abby Chipps Stone for her support and guidance through the writing process. Many thanks to Dawn Cobb, DeeAnn Watt and the Illinois State Museum for allowing the use their lab and archaeological collections. Finally, I have much gratitude for the family and friends that supported me during these two years here, specifically my mother and father, Hank, Cassie, Drew, Emily, Paige, and Shayla. You all kept me sane through this voyage.

A. P. 


\section{CONTENTS}

Page

ACKNOWLEDGMENTS

$\begin{array}{ll}\text { CONTENTS } & \text { ii }\end{array}$

TABLES

FIGURES

CHAPTER I: INTRODUCTION

CHAPTER II: BACKGROUND $\quad 4$

$\begin{array}{ll}\text { Archaeological Context } & 4\end{array}$

$\begin{array}{ll}\text { Bioarchaeological Studies } & 6\end{array}$

$\begin{array}{ll}\text { Clinical Studies } & 10\end{array}$

CHAPTER III: METHODS AND MATERIALS 13

Albany Mounds (11WT1) 13

Kuhlman Mounds (11A163) 13

Dickson Mounds (11F10) 14

$\begin{array}{ll}\text { Methods } & 15\end{array}$

$\begin{array}{ll}\text { CHAPTER IV: RESULTS } & 20\end{array}$

$\begin{array}{ll}\text { Albany Mounds } & 20\end{array}$

$\begin{array}{ll}\text { Schmorl's Nodes } & 21\end{array}$

$\begin{array}{ll}\text { Osteophytosis } & 25\end{array}$

$\begin{array}{ll}\text { Osteoarthritis } & 27\end{array}$

Kuhlman Mounds $\quad 29$

$\begin{array}{ll}\text { Schmorl's Nodes } & 30\end{array}$ 
$\begin{array}{ll}\text { Osteoarthritis } & 36\end{array}$

$\begin{array}{ll}\text { Dickson Mounds } & 38\end{array}$

$\begin{array}{ll}\text { Schmorl's Nodes } & 39\end{array}$

$\begin{array}{ll}\text { Osteophytosis } & 43\end{array}$

$\begin{array}{ll}\text { Osteoarthritis } & 46\end{array}$

$\begin{array}{ll}\text { Co-occurrence } & 47\end{array}$

$\begin{array}{ll}\text { Site Differences } & 47\end{array}$

$\begin{array}{lr}\text { CHAPTER V: DISCUSSION AND CONCLUSION } & 50\end{array}$

$\begin{array}{ll}\text { Differences between Sexes } & 50\end{array}$

$\begin{array}{ll}\text { Differences among Age Groups } & 52\end{array}$

$\begin{array}{ll}\text { Differences among Sites } & 54\end{array}$

$\begin{array}{ll}\text { Conclusion } & 57\end{array}$

$\begin{array}{lr}\text { REFERENCES } & 60\end{array}$ 


\section{TABLES}

Table

Page

1. Number of Individuals Examined in Sites Based on Sex and Age

2. Frequency Data for Albany Mounds Site

3. Fisher's Exact P-values Comparing Sex

4. Fisher's Exact P-values Comparing Age

5. Frequency Data for Kuhlman Mounds Site

6. Fisher's Exact P-values Comparing Sex

7. Fisher's Exact P-values Comparing Age

8. Frequency Data for Dickson Mounds Site

9. Fisher's Exact Test Comparing Sexes

10. Fisher's Exact P-values Comparing Age

11. Fisher's Exact P-values Comparing Individuals in Each Site

12. Fisher's Exact Tests Comparing between Spinal Regions in Sites 


\section{FIGURES}

Figure

Page

1. Map of sites within Illinois $\quad 15$

2. Schmorl's node located on inferior side of thoracic vertebra 16

3. Scoring method for osteophytosis 17

4. Apophyseal facet of thoracic vertebrae encompassed within circle 18

5. Osteoarthritis is identified by three arthroses on the apophyseal facets; 1. porosity, 2. $\begin{array}{ll}\text { osteophytic growth, and 3. eburnation } & 18\end{array}$

6. Albany Mounds arthroses distribution 22

7. Albany Mounds Schmorl's node distribution comparing sex 24

8. Albany Mounds osteophytosis distribution comparing sex 26

9. Albany Mounds osteoarthritis distribution comparing sex 28

10. Kuhlman Mounds arthroses distribution 31

11. Kuhlman Mounds Schmorl's node distribution comparing sex 33

12. Kuhlman Mounds osteophytosis distribution comparing sex 35

13. Kuhlman Mounds osteoarthritis distribution comparing sex 37

14. Dickson Mounds arthroses distribution 40

15. Dickson Mounds Schmorl's node distribution comparing sex 42

16. Dickson Mounds osteophytosis distribution comparing sex 45

17. Dickson Mounds osteoarthritis distribution comparing sex 47 


\section{CHAPTER I: INTRODUCTION}

Bioarchaeology as a field can provide information about past populations that material culture and architecture cannot (Cohen 1977; Larsen 2002; Nelson et al. 2016). Despite this potential, there are answers that continue to elude bioarchaeologists due to inconsistencies in identification and quantification of boney reactive change and the multiple etiologies of some pathologies. For reactive changes to the joints of the vertebral column (spondyloarthropathies), age-related changes can be difficult to distinguish from other causes (e.g., acute trauma, obesity, congenital anatomy, habitual behaviors [e.g., burden bearing, lifting, pushing/pulling]).

However, reactive changes to vertebral bodies have often been used to suggest activity-related differences across subsistence change (e.g., hunting-gathering versus intensive agriculture) and to identify division of labor by sex (Bridges 1989, 1991, 1992, 1994; Lai \& Lovell 1992; Novak \& Šlaus 2011). Cohen (1989) and Jurmain (1990) have cautioned against relying on pathologies as indicative of activities and behaviors involving the spine because of the various etiologies. Additionally, the variability in results across cultural or subsistence contexts is also frequently attributed to cross-cultural differences in the performance of such activities (Bridges 1984).

One way to examine spinal pathology without fruitless results involves the incorporation of multiple pathologies and examining for a co-occurrence. A co-occurrence of pathologies on a particular joint could lead to the realization of a co-association of these pathologies. If pathologies are related to one another in development it could answer the etiology question based on where they are co-occurring in the spine.

There are several different reactive changes on the vertebral body and facets that can be used to assess whether injuries are due to mechanical stress. These are degenerative changes to 
cartilaginous joints (osteoarthritis) and reactive changes to intervertebral disc degeneration and rupture (osteophytosis, and Schmorl's nodes). This thesis is one of the few to incorporate each of these to determine a co-occurrence and possible etiology based on frequency and severity.

Osteoarthritis is a degenerative disease of joints and is the most common form of arthritis (Bridges 1992; Jurmain \& Kilgore 1995; Liu et al. 1995). It is a progressive process (porosity and osteophytic lipping at the joint margins) that eventually leads to the loss of cartilage and synovial fluid creating a bone on bone rubbing (eburnation) (Gellhorn et al. 2013). In the vertebral column, it is confined to the apophyseal facets (Gellhorn et al. 2013). These facets are found on the left and right transverse processes of the vertebral body and make up the synovial joints of the spine, which facilitate flexion, torsion and extension of the spine (Waldron 2008)

Vertebral osteophytosis is the reactive change of bony overgrowths (spurs) on the superior and inferior perimeters of the vertebral body which operate to reinforce compromised intervertebral joints (Liu et al. 1995). Progressive overgrowth results in reduction in vertebral body height and overarching to the point of bridging the intervertebral space. If this persists it can cause a fusion of adjacent vertebrae from the margins. Because of osteophytosis' reactive nature, few papers are written solely focusing on the presence and patterning of the pathology without incorporating another relating pathology such as osteoarthritis, Schmorl's nodes, and scoliosis (Bridges 1994; Masud et al. 1993; Novak \& Slaus 2011; Van der Merwe et al. 2006).

The final pathology that will be examined is the Schmorl's node. These are divots or sharp-margined depressions in the superior and/or inferior surface of the vertebral body as the result of a herniated disc (Dar et al. 2010). A rupture of disc forces the soft nucleus pulposus out of the cartilaginous capsule protecting it and its extrusion in the intervertebral space deforms the surface of the body (Resnick \& Niwayama 1978). 
This research aims to examine a co-occurrence among these three vertebral arthroses indicative of degenerative joint disease in order to provide a pattern of pathology that may aid in identifying etiology. Osteoarthritis of the apophyseal facets, osteophytosis, and Schmorl's nodes were examined in the spines of skeletal remains from three sites; Albany Mounds, Kuhlman Mound, and Dickson Mounds. The sites are temporally sequential and are located in the same geographic area, but differ in culture, time period, and subsistence economy. The questions that guide this thesis are as follows:

- Is there a co-occurrence among Schmorl's node, osteophytosis, and osteoarthritis in joints of the population sample?

- Are there intra-site differences in frequency and distribution of these pathologies when populations are separated into sex and age categories?

- Are there inter-site differences in frequency and distribution of pathologies?

This thesis sheds light not only on a methodological approach, but also contributes to existing literature on spinal pathology within pre-Columbian populations. Chapter II will go over the archaeological context of west-central Illinois and nearby during the Middle Woodland, Late Woodland, and Mississippian time periods. This chapter will also give an overview of the research that has been performed using Schmorl's nodes, osteophytosis, and osteoarthritis within the region as well as research that has examined patterning of these arthroses in association with particular groups of people. Following this background, Chapter III provides site descriptions as well as the methods utilized in the research. Results of the research are located in chapter IV and interpretations of these results will be discussed with future work and concluding remarks. 


\section{CHAPTER II: BACKGROUND}

\section{Archaeological Context}

The Eastern Woodlands is defined as the area in the United States from the Great Lakes to the north, the Gulf of Mexico to the south, the Atlantic to the east, and the Great Plains to the west. The time prior to European contact in the Eastern Woodlands has been classified into different time periods based on a number of factors including tool technology, settlement patterns, subsistence economies, and cultural practices such as mortuary patterning (Munoz et al. 2014; Rose 2003; Scarry 2003). West-central Illinois was home to Native Americans prior to European contact including the time periods of the Middle Woodland, Late Woodland, and Mississippian periods due to the abundance of natural resources as well as fertile ground for crop cultivation.

The Middle Woodland period (150 BCE - CE 400) was marked by the suggested unified culture known as the Hopewell based on the stylistic similarities in ornate artifacts found in association with the time period across the region as well as throughout the eastern United States (Tainter 1977). Procurement of food during this time involved "intensive harvest collecting" as proposed by Struever (1968) in which Middle Woodland people utilized a limited number of highly fruitful wild food resources. Food items such as maygrass and a knotweed species were cultivated in their gardens while they made use of other food sources outside of their villages like nuts, white tailed deer, and turkey (Asch et al 1979). Agriculture was not affiliated with the time period as only scarce amounts, if any, of maize were found prior to CE 900 (Simon 2017). In Illinois, starchy seeds increased in frequency during this time (Rose 2003) before maize was introduced to the region. 
The Late Woodland period of west-central Illinois (CE 450 - 1000) continuing after Middle Woodland would first appear to show little to no difference in subsistence economy from Middle Woodland sites except in the intensification of crop cultivation, increased use of aquatic resources marked, and by the presence of storage pits (Asch et al 1979; Garner 1991, Nolan 1995). A recent upswing in Late Woodland site research has provided evidence that the peoples of the Late Woodland period had a culture complexity different from Middle Woodland (Rose 2003). Cultural changes from Middle Woodland to Late Woodland included the loss of elaborate decorations and burial goods that were seen during the Hopewell polity, but culture became more variable cross-regionally (Asch et al 1979, Garner 1991, Rose 2003). Small starchy seeds such as maygrass and knotweed and oily seeds such as sumpweed are more commonly found within Late Woodland sites, while seeds from maize could be entirely absent from sites or be found in small numbers (Garner 1991, Green \& Nolan 2000). However, As time went on throughout Late Woodland, people shifted from relying on nuts and local cultigens to the cultivation of maize alongside starchy seeds (Green \& Nolan 2000). There is no evidence of intensive agriculture in the Late Woodland, but as population increased through this period, the reliance on a more stable cultivated crop increased (Asch et al 1979).

As the practice of agriculture became a more prominent source of food, the time was classified as the Mississippian period (CE 800 - 1650). Population increased as well as disease because higher population densities made spread of diseases easier and perhaps deadlier (Goodman et al 1980; Goodman, Armelagos, and Rose 1984; Goodman, Lallo, Armelagos, and Rose 1984; Larsen 1995). Stress increased through the Mississippian Period leading to an overall decrease in health in the form of higher frequencies of infectious, degenerative, and metabolic lesions (Lallo 1963). Scarry (1993) reviewed crop strategies of the American Bottom region, just 
south of west-central Illinois. Findings showed that maize production was added to existing subsistence strategies which entailed the cultivation of the Eastern Agricultural Complex during the emergence of the Mississippian period (CE 800-1000) (Rose 2003). As the period progressed into Middle Mississippian, maize production intensified, while starchy seed production seemed to stabilize (Rose 2003; Scarry 1993). Lallo’s (1973) analysis of the Middle Mississippian component of Dickson Mounds suggested that there was a general decrease in the use of projectile points and blades affiliated with hunting with a complimentary increase in the hoe and other maize processing tools.

This project will take subsistence strategies into consideration when discussing the results of this research. If the majority of time was spent on subsistence then one could predict that some pathologies that are observed within skeletal samples could be directly associated with the subsistence economy of that time period.

\section{Bioarchaeological Studies}

Changes in health across temporal periods in Illinois have been studied through the examination of linear hypoplasia, infant mortality rates based on demographics, and pathology relating to disease (Cook 1976, 1979; Goodman, Lallo, Armelagos, and Rose 1984; Nelson et al. 2016).

Studies in Illinois and elsewhere have also discussed workload and degenerative processes associated with agriculture (Bridges 1989; Larsen 1995). They examined varying degrees of frequency and severity of these pathologies presenting in skeletal material across regions. No singular pattern can be determined from examining populations cross-regionally, leading this research to focus on the specific region of west-central Illinois and nearby in order to allow for patterning to be determined. 
Using osteoarthritis to make inferences about population behavior has been undertaken for several decades (Boyd \& Boyd, 1997; Lieverse, 2007; Welzein, 2003). However, more focus is usually given to the osteoarthritis on the vertebral bodies rather than the apophyseal facets (Sofaer-Derevinski 2000). Bridges' (1994) examination of vertebral osteoarthritis within an Archaic sample and a Mississippian sample from the Middle Tennessee River valley discussed the patterning of spinal osteoarthritis and osteophytosis development. Bridges found the highest frequency of osteophytosis in the lumbar region with second highest frequency in the cervical. Osteoarthritis within the whole sample was less variable, but was still highest in the lumbar region. These results led to the conclusion that the forces of joint deterioration on the apophyseal facets (osteoarthritis) were more similar throughout the spine than the forces that led to osteophytosis of the vertebral body. Cohen and Armelagos (1984) noted a similar pattern of decrease in osteoarthritis with the transition to agriculture, however other studies have disagreed (Goodman, Lallo, Armelagos, and Rose 1984; Lallo 1973). Lallo (1973) found in the case of the Dickson Mounds sample, a general increase of appendicular osteoarthritis, including vertebral osteoarthritis, among the Mississippian population when compared to their Late Woodland counterparts within the site. The analysis of the Kubinski site in Illinois by Pestle and colleagues (2007) led to the observation of osteophytosis within the spines of the individuals found there.

Not surprisingly, the highest frequency was equally observed in the lumbar and cervical regions.

Sofaer-Derevinski (2000) examined two populations from the UK with known sex-based divisions of labor. They observed the $\mathrm{C} 7 / \mathrm{T} 1$ joint to be most vulnerable as it changes from weight-bearing to more rotating (p.350). Their research found more osseous changes in the sample from Ensay where activities were known to be laborious and sex-divided. They found less stressed skeletons from Wharram Percy and less statistical differences between males and 
females. Here it is documented that while social norms required men and women to carry out different labor tasks, the work at home was more fluid.

Bridges (1994) pointed out that finding significant variation is a challenge without a standardization of scoring for osteoarthritis and osteophytosis. This challenge is temporarily remedied in this thesis because each site is observed and scored in the same way so there no discrepancies among these particular sites. One explanation to these differences could be from the differences in work being done across regions.

Much like the difficulty in finding specific causes of osteoarthritis and osteophytosis within pre-Columbian populations, Schmorl's nodes can also present a dilemma in cause determination (Burke 2012). Trauma, age, disease, and other processes can promote Schmorl's node formation, but what is unknown is which one correlates to a specific node. Frequency and patterning can vary within research of different population samples. Novak (2011) analyzed a small population of people from the Medieval time period in Croatia. His findings of high Schmorl's node frequencies in males, but higher frequencies of osteoarthritic changes in females suggested a sexbased division of intensive labor, but a longer lifespan of females in the sample based on the known activities of females within the population.

While researching the etiology of Schmorl's nodes, Dar and colleagues (2010) found Schmorl's nodes more frequently within the thoracic region of 240 individuals within the Hamann-Todd collection specifically through T7-L1. They went on further to include the portion of the vertebrae with the highest frequency of Schmorl's nodes and proposed that vertebrae development early on in life played a role in Schmorl's node development. However, as this research only focused on adults (presence of third molar), no juveniles were examined for Schmorl's nodes to corroborate Dar et al.'s (2010) research. 
As previously mentioned, there are multiple processes for Schmorl's node formation. Age has commonly been examined, although there have been no positive correlations to age and Schmorl's nodes (Burke 2012). Trauma and repetitive stresses such as lifting objects the same way frequently over a lifetime can lead to Schmorl's nodes. Lai and Lovell (1992) examined skeletal remains from the Hudson's Bay Company Fur Trade Post. From the remains, they were able to argue that the three individuals classified as Native Americans were voyageurs for the company due to combined frequency of Schmorl's nodes, osteophytosis, osteoarthritis and robusticity of muscle attachments.

A preliminary investigation on Schmorl's nodes was conducted to determine if non-activity related factors could be considered influential in Schmorl's node formation (Weiss, 2005). A skeletal sample of seventy-seven remains was analyzed from two different populations, one population having a history of activities that were straining to the spine. The results projected two important points. The first being that the population with spine straining activities had a higher frequency of SN indicating mechanical stress as a large factor in formation. The second point made was that there was a lack of correlation to SN and body size, age, or sex in this research. This helps strengthen the argument of non-activity related factors having little influence in SN frequency. However, it was noted acute trauma could play a factor in frequency as much as mechanical stress as both can coincide with the associated labor performed.

Some studies specifically use pathology to determine the lifeways of a population, but it has been cautioned not to rely on arthroses such as osteoarthritis, osteophytosis, and Schmorl's nodes to indicate lifeways and behaviors of the population (Cohen 1989; Jurmain 1990). This is due to some researchers' inabilities to make distinctions from data as seen in Cohen's (1989) study of subsistence patterns through examination of osteoarthritis in populations. However, inferences 
can be made if they meet "fairly rigorous criteria for a study of activity induced pathology." (Lai and Lovell 1992, 226). Bridges (1989) found that Mississippian remains had stronger, thicker long bones than Archaic remains suggesting that the agricultural activities of the Mississippian culture were more strenuous than the Archaic hunting and gathering activities in the region. There was also an aspect of female arm robusticity that supported division of labor with women processing the corn.

Novak and Slaus (2011) presented a study on vertebral pathologies in two populations in Croatia. Extensive ethnographic data on their two samples showed differences in labor intensity, but a similarity in a sex-divided labor force. Schmorl's nodes were noted to be more common in the thoracic region than the lumbar, while osteophytosis showed an increasing trend through the spine; the cervical region having the least amount of osteophytosis and the lumbar with the highest frequency. Osteoarthritis had peak frequency within the lumbar region of both populations with secondary peaks in the cervical and thoracic regions. Their data showed the skeletal sample from Koprivno, a rural community, had more demanding living conditions than Sisak, an urban community, due to the significant frequency differences of Schmorl's nodes, osteophytosis and osteoarthritis. Higher frequencies of Schmorl's nodes and osteoarthritis in males of both samples also provided the argument for sexual division of labor.

\section{Clinical Studies}

It's been suggested that clinical studies tend to under-represent joint changes since they are performed radiographically. This can bring a new challenge archaeological studies do not have as identifying slight or moderate changes to the bone can be more difficult. However, using clinical studies as a guide to distribution patterns within populations with known activities and 
behaviors, can help with archaeological work when context of a population may be less available.

Seidler and colleagues (2001) examined 229 male patients in Frankfurt and the surrounding area for spondylosis patterning. The patients all had radiographically confirmed spondylosis in their lumbar spines, which commonly refers to the general degeneration of the vertebral body, which included osteophytic development. Among these patients, 135 also had acute herniation of the lumbar vertebral discs. Their results concluded that workloads involving heavy lifting and tremendous forward bending were associated with spondylosis and acute disc herniation in the lumbar spine. If this study used spondylosis to define osteophytosis rather than the general degeneration of the spine then this could mean that a co-association between osteophytosis and herniated discs. If Schmorl's nodes had been present in joints with herniated discs, an association between osteophytosis and Schmorl's nodes may also have existed within the study.

Other clinical studies performed on an arthrosis being observed within this research includes Sward and colleagues (1990) examination of Schmorl's nodes within the thoracic-lumbar spines active athletes. They concluded that athletes that put greater stress on their backs had increased risks of trauma and damage to their spines (Sward et al. 1990). Gymnasts and wrestlers had the highest frequencies of Schmorl's nodes in their spines, but all athletes examined had higher frequencies than a non-athlete group. Peak frequency was observed at the T12 vertebrae, but Schmorl's nodes were seen from the T7-S1. Their findings showed a significant correlation between back pain, Schmorl's nodes, and load-bearing activities.

Research in patterns of osteophyte development and frequency has shown highest frequency to be within the lower thoracic and lumbar regions (O’Neill et al 1999; Seidler et al. 2001). 
O'Neill and colleagues (1999) found males and females in their study to have osteophytosis most frequently identified at the T9-10 joint.

Most clinical studies have restricted analysis to the lower back particularly the thoracic and

lumbar regions of the spine. As this thesis will examine the entire spinal column from atlas to the last lumbar vertebrae, some patterns may differ than the ones found in the above studies. 


\section{CHAPTER III: METHODS AND MATERIALS}

In the examination of osteoarthritis, osteophytosis, and Schmorl's nodes co-associating in vertebral joints, three temporally differing sites within Illinois were used that are housed at the Illinois State Museum. The museum's existing records on the sites were used for age and sex determination. Extensive examination had been performed for each site allowing for confidence in using the records. Only individuals with assigned sexes and age ranges were used. Age groups were comprised to represent young adults, middle adults, and old adults. Photos were taken on a case to case basis with a phone to keep scoring consistent and to provide photo evidence of pathology.

\section{Albany Mounds (11WT1)}

Working as a proxy for the Middle Woodland period, a skeletal sample from Albany Mounds (200 BCE-CE 400) was examined (Herold 1971). Located on the east bank of the Mississippi River in Albany, Illinois (Figure 1), this Hopewellian community practiced a huntergatherer technique in food procurement. In all, 81 mounds define the site however, only 13 burial mounds were excavated resulting in a 221 individuals skeletal sample. Mound 9 contained 101 burials and is where the majority of the remains examined for the research were excavated. Preservation issues was a concern for this skeletal sample and led to a smaller usable sample size compared to other population samples examined for the research.

\section{Kuhlman Mounds (11A163)}

Kuhlman Mounds, used as a proxy for Late Woodland people in west-central Illinois, is located on the eastern bluffs of the Mississippi River in Adams County, Illinois (Figure 1) (Atwell \& Conner 1991). The mound group is located adjacent to Kuhlman village allowing for 
information on subsistence patterns of these particular people to be inferred from past excavations of the village. Based on ceramic analysis, the village and mounds are dated to have been used from CE 600-900 (Conner \& Morgan 1991). Overall about 260 individuals were found at the Kuhlman Mounds (Atwell 1991). Mound 1 contained approximately 185 remains, and is where the majority of remains examined here were excavated.

\section{Dickson Mounds (11F10)}

The population sample used as a proxy for the Mississippian period came from the Dickson Mounds site sample. The mounds, making up several mortuary contexts, are located in Fulton County on a bluff overlooking the Illinois River (Figure 1) (Milner \& Buikstra 1989). In total, roughly 1,100 individuals have been excavated from the site, however, it is believed that over 3,000 individuals could have been contained within the mortuary complex (Harn 1971). The cemetery is thought to have been in use for several centuries and stopped being used c.a. CE 1300. Stress seemed to increase at Dickson Mounds from beginning of occupation up to the Middle Mississippian period (Goodman et al. 1980; Goodman, Armelagos, and Rose 1984; Goodman, Lallo, Armelagos, and Rose 1984). Because of the large number of excavated remains, the researcher handpicked an equal number of males and females that had almost complete spines to be analyzed. The presence of pathology was not selected for in order to remain unbiased in that fashion, however a bias was still established in choosing to study individuals that maintained complete to almost complete vertebral columns. Due to this large sample, more individuals within this site were able to be examined compared to the other two sites that may have had more preservation issues. 


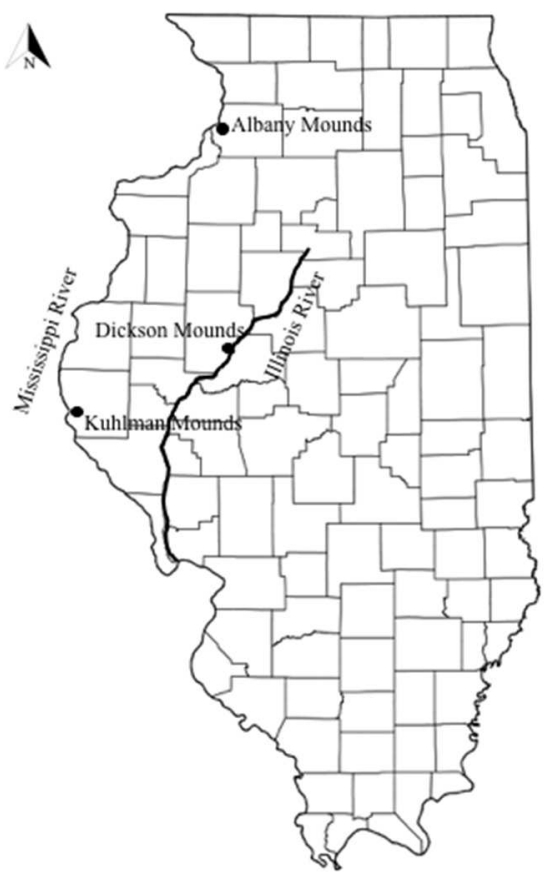

Figure 1. Map of sites within Illinois

\section{Methods}

Based on the inventory information provided by the Illinois State Museum, 30 males and 30 females were selected to be examined. Once boxes were accessed, it was determined that due to preservation issues, some individuals selected were not able to be examined. Final count of the population for Dickson Mounds includes 29 males and 23 males to create a sample size of 52 adults with spines present for examination. Kuhlman Mounds and Albany Mounds skeletal materials were evaluated for individuals that met the criteria of having at least one distinguishable vertebra (i.e. T12 or C2) and then examined for arthroses.

Two types of joints will be examined, the synovial joints and the symphyseal joints of the spine. Schmorl's nodes and osteophytosis develop in the symphyseal joints made up of the vertebral bodies, while osteoarthritis develops in the synovial joints made up of the apophyseal facets on the transverse processes in the spine (Waldron 2008). In order to distinguish a co- 
occurrence of Schmorl's nodes, osteoarthritis, and osteophytosis in the spine, each vertebra is scored as a joint. If there was a vertebra missing, the joint was assessed and scored using the adjacent vertebra that makes up the other portion of that particular joint. Only individuals with at least one distinguishable vertebrae (e.g. T1,T12) were recorded in the data collection. Schmorl's nodes were examined for on the sympheseal joints of the spinal column and scored with a nominal number based on their presence in a joint. No presence resulted in the scoring of a 0 , while presence of a Schmorl's node in the joint received a score of 1 (Figure 2).

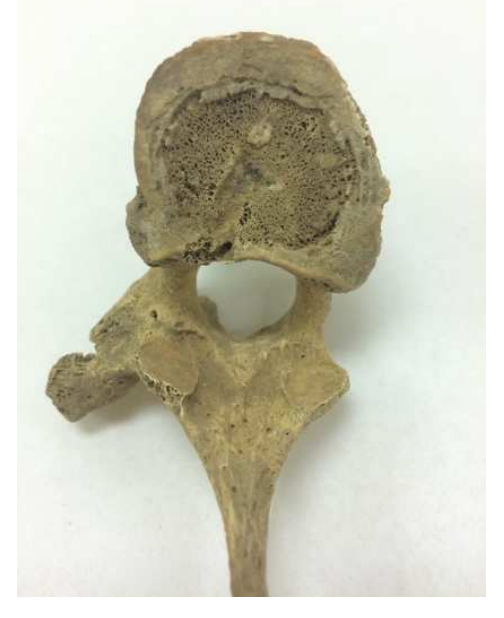

Figure 2. Schmorl's node located on inferior side of a thoracic vertebra

Van der Merwe et al. (2006) combined the methods of Nathan (1962) and Stewart (1958) to visually assess and score osteophytosis in the spinal column. This method was adapted for the research here (Figure 3). Vertebral joints were scored 0-4; 0 indicated no osteophytosis, lindicated single points of osteophyte development and slight lipping, 2 indicated outward growth of osteophytes, and 3 indicated advanced lipping on the vertebral body and osteophytes showing a "bird beak" appearance. This is when the osteophytes have curved upwards or downwards in the direction of the closest intervertebral space. The final score, 4 , indicated that osteophytes of two or more adjacent vertebrae had fused together. For each joint, the more 
severe score was assigned in order to obtain an understanding of severity within each individual joint. When accounting for the presence of osteophytosis in the joints, any score above 0 was counted as the presence of osteophytosis.
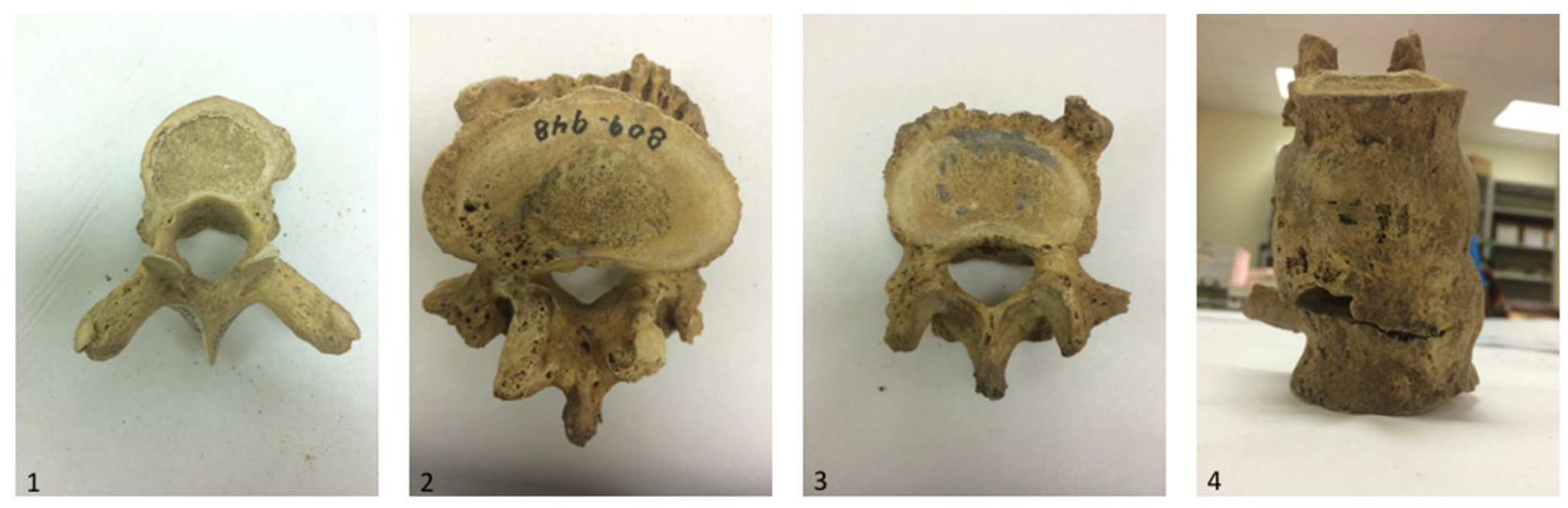

Figure 3. Scoring method for osteophytosis; 1. Single point of osteophyte development on vertebral body, 2. Outward growth of osteophytes, 3. Advanced lipping and curved growth towards adjacent vertebra, 4. Complete fusion of adjacent vertebrae from osteophyte growth

The apophyseal facets of the vertebral column (Figure 4) were examined for osteoarthritis. Osteoarthritis scoring (Figure 5) was similar to Schmorl's node scoring as nominal numbers were assigned, but assignment was based on presence of pathologies indicative of osteoarthritis. A score of 0 indicated the absence of any osteoarthritis. A score of 1 indicated porosity or pitting, 2 indicated osteophyte development on the apophyseal facet and 3 indicated eburnation, a pathology that is perhaps pathognomic for osteoarthritis (Waldron 2008). In order to accurately identify osteoarthritis, I required at least two out of the three pathologies indicative of osteoarthritis to be present on the joint. This is similar to the Standards method, but simplified to meet the research questions and provides a better understanding of the pathologies present. By requiring at least two pathologies be present, it can be better argued for the presence of osteoarthritis occurring on the facets rather than reactive change from natural wear and tear (Waldron 1991). All three were not required for diagnosis because in some cases, osteophytes 
have not been found on the facets even in the most severe cases of known osteoarthritis

(Gellhorn et al. 2012).

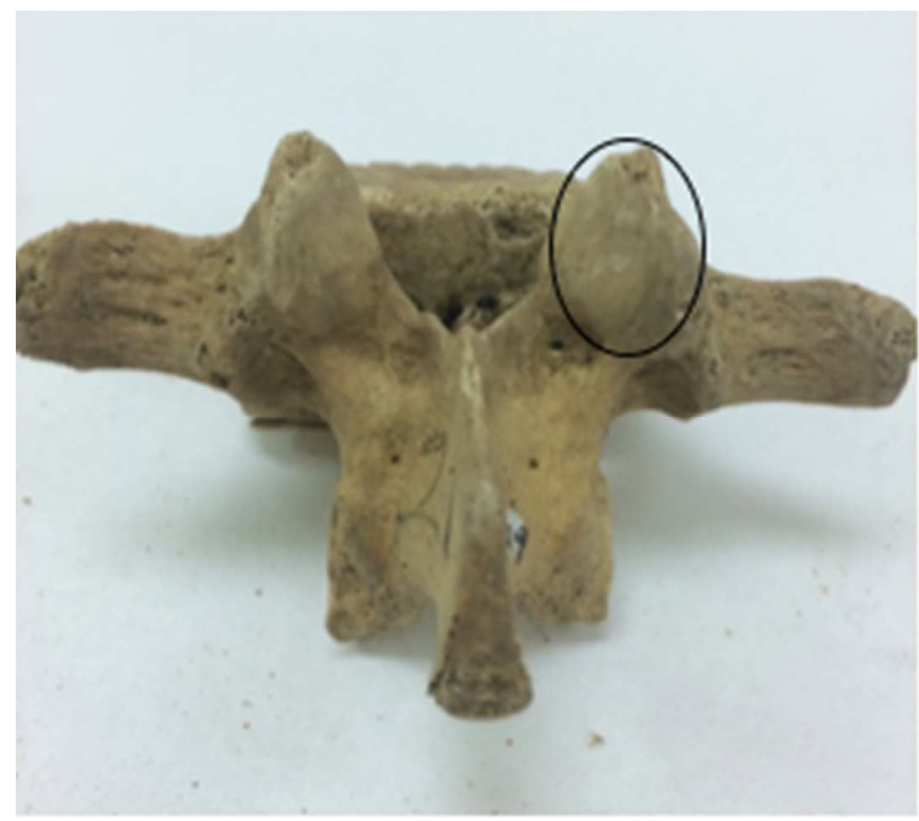

Figure 4. Apophyseal facet of thoracic vertebrae encompassed within circle
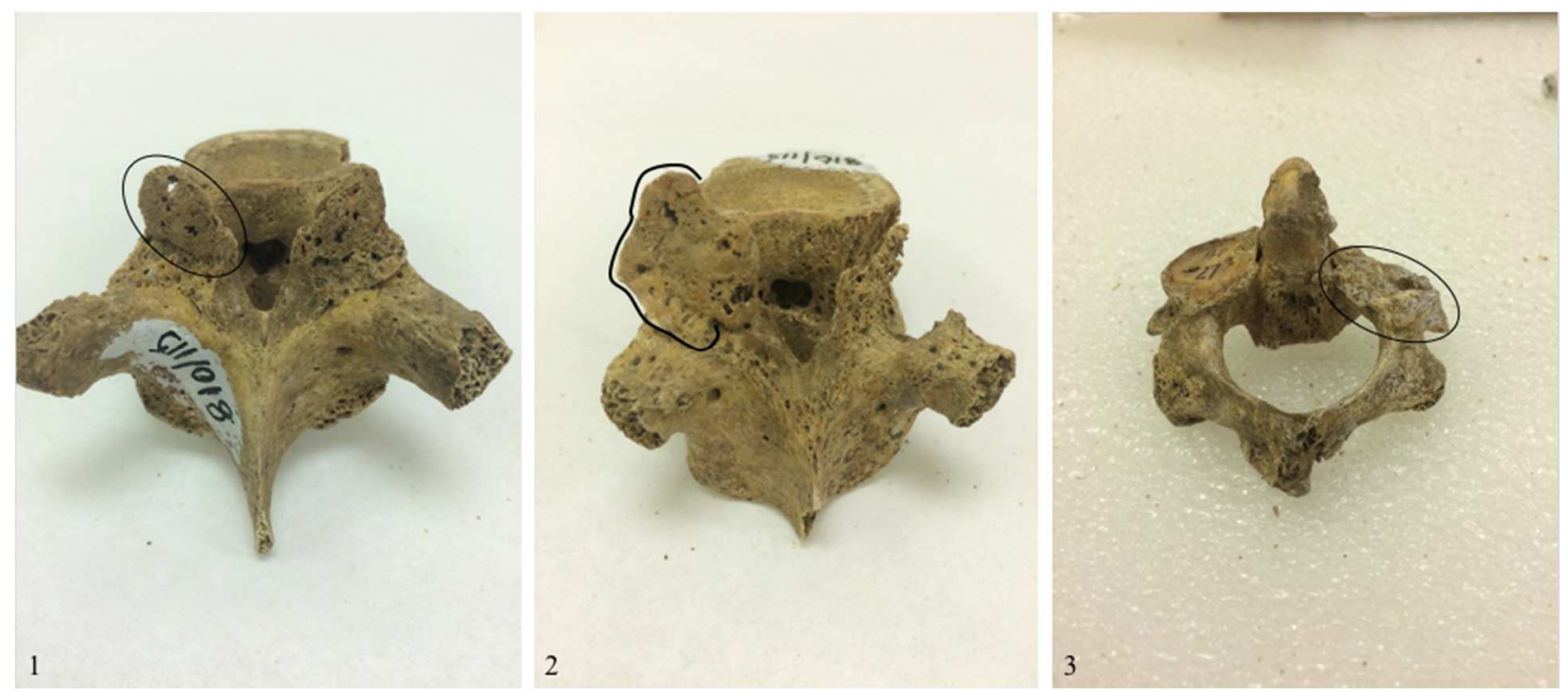

Figure 5. Osteoarthritis is identified by three arthroses on the apophyseal facets; 1. porosity, 2. osteophytic growth, and 3. eburnation

As previously explained, a co-association of these arthroses could be potentially helpful in investigating the behaviors and activities of a population. In order to analyze data, an 
examination of each vertebral joint for highest frequency was implemented as well as general regions within the spine (e.g. cervical region). Schmorl's nodes would be the clear indication of mechanical stress as non-activity factors such as age has minimal influence on their formation (Weiss 2005). Each vertebra was first scored separately using a Standards (Buikstra \& Ubelaker 1994) template and then the joints were scored using the greater of the two scores on each vertebrae making up the joint score for the arthroses. The data was then compared between sex, age group, and temporal period in order to determine patterns of frequency and severity as well as to determine if a co-occurrence exists and what the significance of that co-occurrence may be. Univariate statistical analysis was used to test for significance in pathology presence or absence. Fisher's exact test was used to examine significance between males and females within each site, between sites, and age groups between sites. Fisher's exact tests were used to examine significance $(p=<0.05)$ between frequencies in age group joints within the same site. 


\section{CHAPTER IV: RESULTS}

Upon examination of the skeletal samples within Albany Mounds (11WT1), Kuhlman Mounds (11A163), and Dickson Mounds (11F10), a total of 123 individuals were included in the study. Individuals were categorized by sex and age as shown in table 1 . The results are presented graphically showing each joint's frequency in order to understand the frequency and distribution of each arthroses in the spine. Analysis of sex and age differences use individuals as well as joints affected for understanding of who is actually affected by each arthrosis. Table 1. Number of Individuals Examined in Sites Based on Sex and Age

\begin{tabular}{|lllllll|}
\hline & \multicolumn{2}{l}{ Albany Mounds } & \multicolumn{2}{l}{ Kuhlman Mounds } & \multicolumn{2}{l|}{ Dickson Mounds } \\
& Male & Female & Male & Female & Male & Female \\
\hline Young Adult & 15 & 4 & 12 & 11 & 11 & 12 \\
Middle Adult & 3 & 5 & 6 & 5 & 16 & 8 \\
Old Adult & 1 & 0 & 4 & 3 & 2 & 3 \\
Total & $\mathbf{1 9}$ & $\mathbf{9}$ & $\mathbf{2 2}$ & $\mathbf{1 9}$ & $\mathbf{2 9}$ & $\mathbf{2 3}$ \\
\hline
\end{tabular}

\section{Albany Mounds}

As suggested in the previous chapter, the poor preservation presented the researcher with challenges in regards to sample size and viable vertebrae to be examined. Nevertheless, data was collected and frequency of individuals exhibiting theses arthroses within Albany Mounds are presented in table 2 . There were 29 individuals that met criteria for examination, 9 females, and 19 males. 
Table 2. Frequency Data for Albany Mounds Site

\begin{tabular}{|c|c|c|c|c|}
\hline & & Age & & \\
\hline & Young Adult & Middle Adult & Old Adult & Overall Total \\
\hline Sample adults & 20 & 8 & 1 & 29 \\
\hline $3=$ Total indv. with Schmorl's nodes & & & & $10 \%$ \\
\hline Male & $1(7 \%)$ & 0 & 0 & 1 \\
\hline Female & 0 & $2(40 \%)$ & 0 & 2 \\
\hline Unknown & 0 & 0 & 0 & 0 \\
\hline $7=$ Total indv. with Osteophytosis & & & & $24 \%$ \\
\hline Male & $2(13 \%)$ & 0 & 0 & 2 \\
\hline Female & $2(50 \%)$ & $3(60 \%)$ & 0 & 5 \\
\hline Unknown & 0 & 0 & 0 & 0 \\
\hline $6=$ Total indv. with osteoarthritis & & & & $21 \%$ \\
\hline Male & 0 & $1(33 \%)$ & $1(100 \%)$ & 2 \\
\hline Female & $1(25 \%)$ & $3(60 \%)$ & 0 & 4 \\
\hline Unknown & 0 & 0 & 0 & 0 \\
\hline
\end{tabular}

\section{Schmorl's Nodes}

Schmorl's nodes were observed in 10\% (3/29) of the population, which was comprised of one young adult male and two middle adult females. As only five out of 142 joints examined had observed Schmorl's nodes within sample (4\%), only visual assessments can be made rather than statistical analysis. In total three individuals presented with at least one Schmorl's node in their vertebral joints. Two of the three individuals (one young adult male and one middle adult 
female) with Schmorl's nodes exhibited them in the L2/L3 joint marking it as the highest frequency of Schmorl's node observation within the population sample.

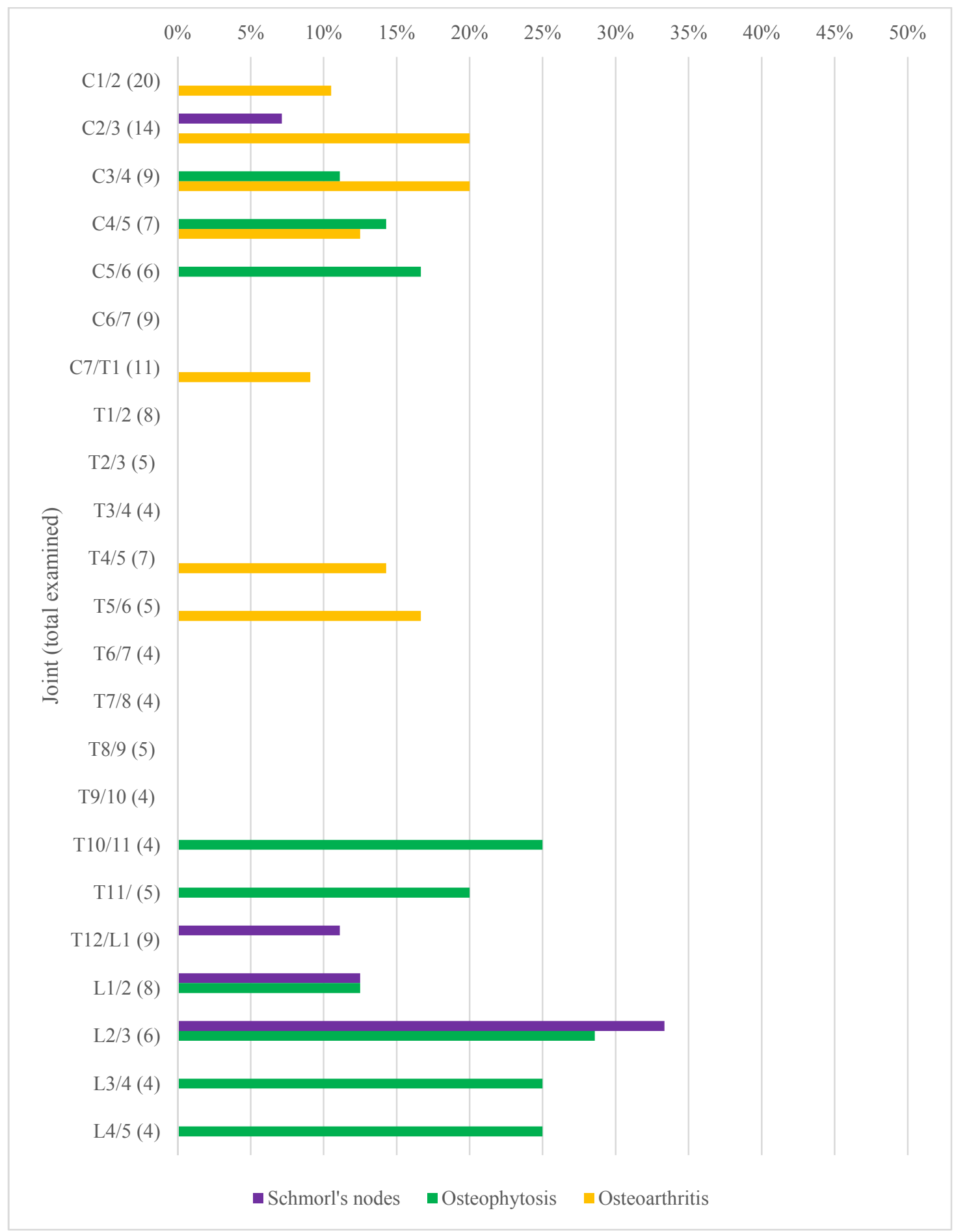

Figure 6. Albany Mounds arthroses distribution 
There was no statistical difference $(\mathrm{p}<.05)$ for individual males and females with Schmorl's nodes nor for joints in males and females (table 3). Females in this sample exhibited Schmorl's nodes in 22\% (2/9) of individuals and 6\% (3/52) of joints (figure 6$)$. The three Schmorl's nodes were observed in one cervical joint, one T12/L1, and one lumbar joint (figure 6). Males only exhibited Schmorl's nodes in the lumbar region. Males exhibited Schmorl's nodes in $5 \%(1 / 19)$ of individuals and in $2 \%(2 / 84)$ joints within the sample.

Table 3. Fisher's Exact P-values Comparing Sex

\begin{tabular}{|lll|}
\hline & Fisher's exact - individuals & Fisher's exact - arthroses \\
\hline Schmorl's nodes & 0.2344 & 0.3783 \\
Osteophytosis & $0.0196^{*}$ & $0.0437^{*}$ \\
Osteoarthritis & 0.0638 & 0.3448 \\
\hline
\end{tabular}

Note: * indicates significance $(p<.05)$ 


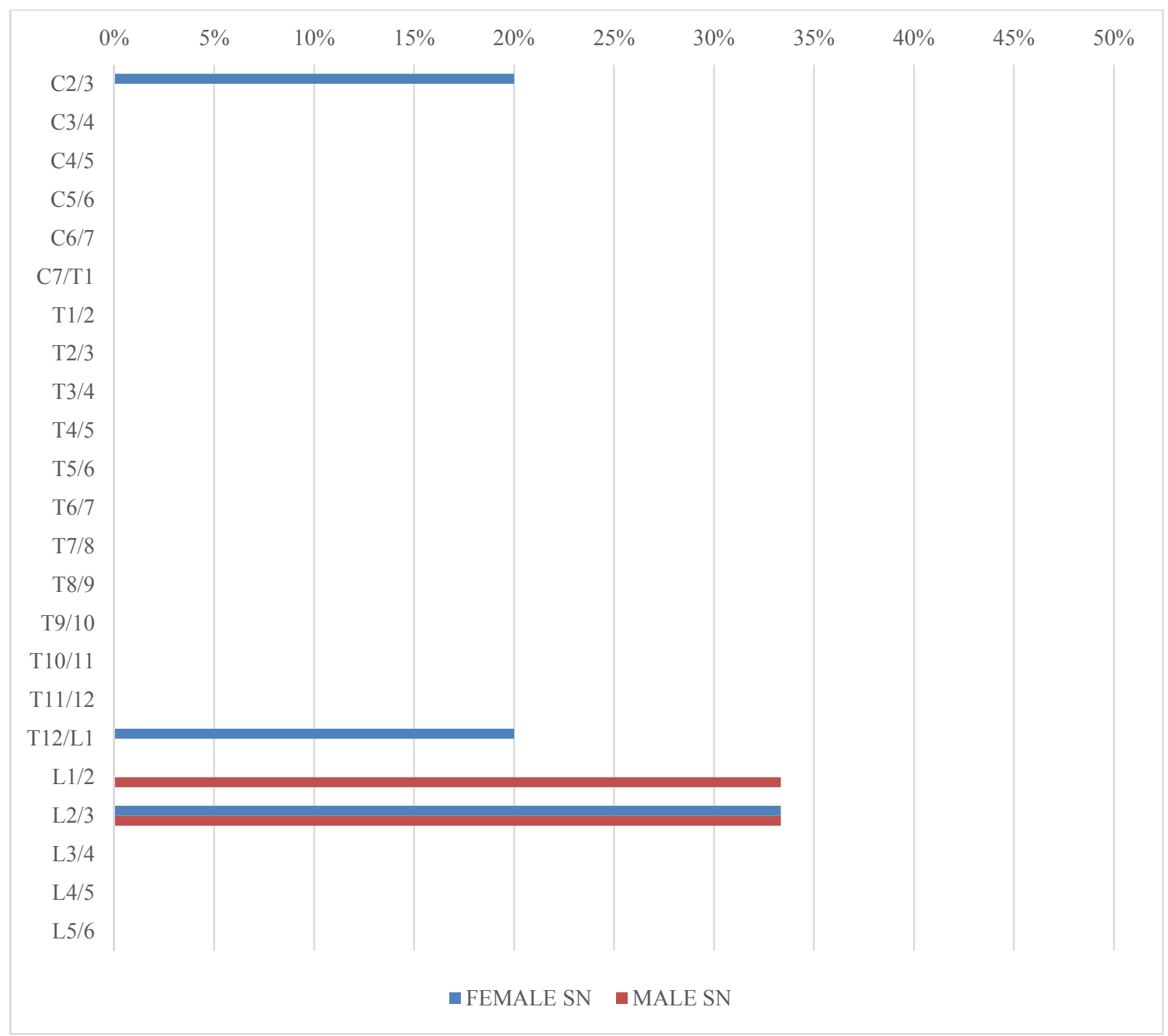

Figure 7. Albany Mounds Schmorl's node distribution comparing sex

There was no statistical significance between any of the frequencies of joints exhibiting Schmorl's nodes in the age groups (table 4). Middle Adults at Albany Mounds were the most affected by Schmorl's nodes as 25\% (2/8 individuals) of the category exhibited at least one Schmorl's node in their spine. Within the Young Adult category of Albany Mounds, Schmorl's nodes were observed the most frequently in the lumbar region (2/15 joints, $13 \%)$. This was the only region in this category with observed Schmorl's nodes. Similarly, Middle Adults in this sample also showed the highest frequency in the lumbar region (1/7 joints, $14 \%)$. If the T12/L1 joint is taken out of the region and analyzed on its own, the joint had a $33 \%$ frequency $(1 / 3$ 
joints) for Schmorl's node observation. There was not enough data for Old Adults in the sample to analyze. There was a general trend of increasing pathology frequency down the spine for Young and Middle Adults.

Table 4. Fisher's Exact P-values Comparing Age

\begin{tabular}{|c|c|c|c|c|}
\hline & & Young Adult & Middle Adult & Old Adult \\
\hline \multirow{3}{*}{ Schmorl's nodes } & Young & & & \\
\hline & Middle & 0.3264 & & \\
\hline & Old & 1 & 1 & \\
\hline \multirow{3}{*}{ Osteophytosis } & Young & & & \\
\hline & Middle & 0.1646 & & \\
\hline & Old & 1 & 1 & \\
\hline \multirow{3}{*}{ Osteoarthritis } & Young & & & \\
\hline & Middle & $0.0012 *$ & & \\
\hline & Old & $0.0005^{*}$ & 0.0993 & \\
\hline
\end{tabular}

Note: $*$ indicates significance $(p<.05)$

\section{Osteophytosis}

Osteophytosis was observed in $24 \%$ of individuals examined (7/29 individuals) and $6 \%$ of joints examined (10/164 joints). Osteophytosis had the highest frequency within the lumbar region $(28 \%, 5 / 18$ joint $)$ and the lowest frequency in the thoracic region $(4 \%, 2 / 54$ joints) as osteophytosis was only observed in the lower thoracic joints of T10-12. There were four joints that had observed cases of severe osteophytosis, which were located in three individuals.

Not only were there significantly more females with osteophytosis than males $(\mathrm{p}=.0196)$, but females also had significantly higher frequencies of osteophytosis within their joints observed ( $\mathrm{p}=.0134)$ (Table 3). 55\% (5/9) of females exhibited osteophytosis and $11 \%$ of their joints (7/62) were affected (figure 8 ). Females had highest frequency of osteophytosis in the 
lumbar region $(18 \%, 2 / 11$ joints) and second highest frequency in the cervical region $(15 \%, 3 / 20$ joints). Males exhibited osteophytosis only in the lumbar region with a $25 \%$ (3/12 joints) frequency. $11 \%(2 / 19)$ of males exhibited osteophytosis and $3 \%$ of their joints (3/98) were affected.

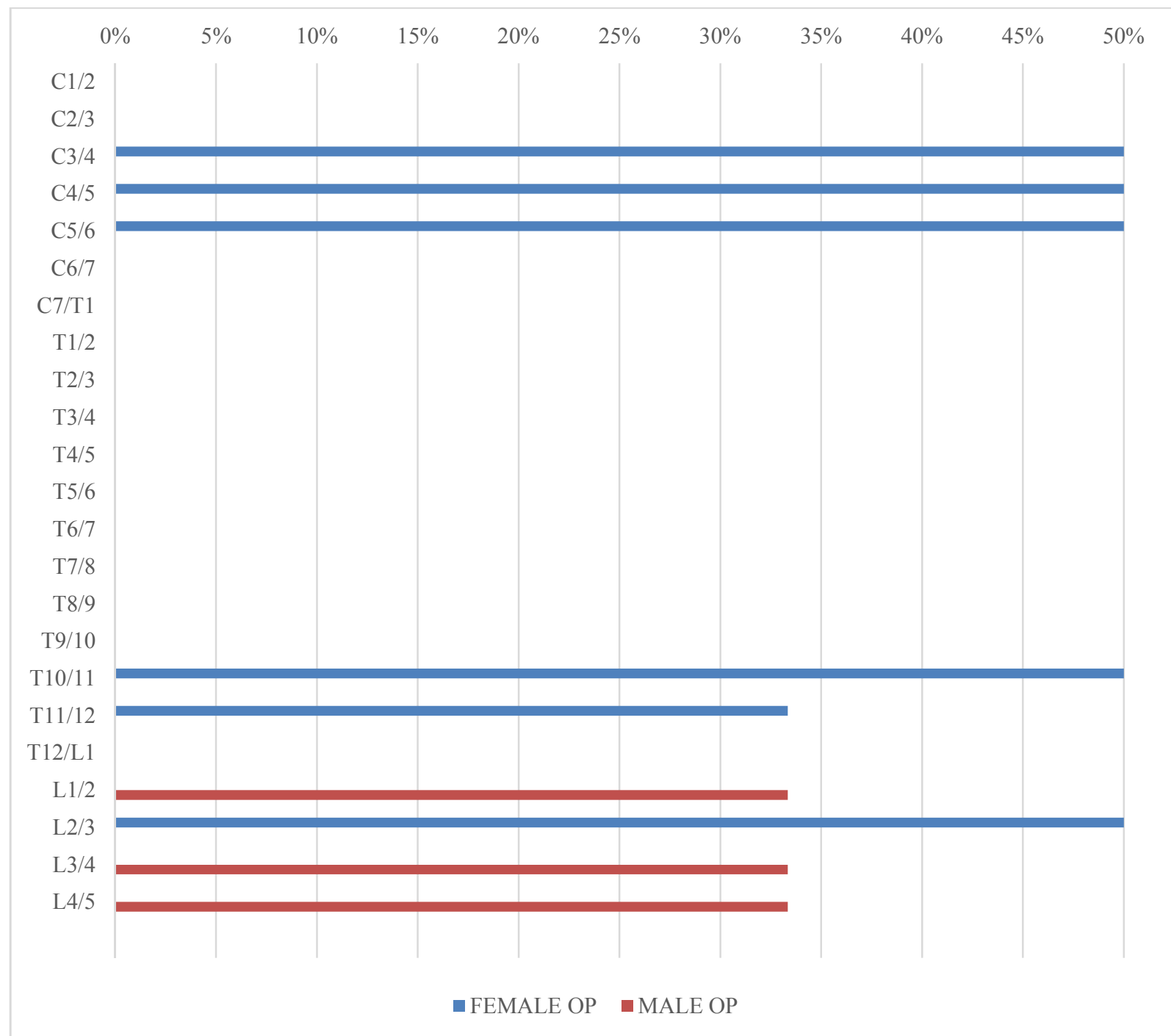

Figure 8. Albany Mounds osteophytosis distribution comparing sex

There was no statistical significance between any of the frequencies of joints exhibiting osteophytosis in the age groups (table 4). Middle Adults exhibited the highest frequency of individuals with osteophytosis ( $38 \%, 3 / 8$ individuals). Osteophytosis had the highest observed frequency in the lumbar region $(3 / 15,20 \%)$ in Young Adults with the thoracic region having the 
second highest frequency. In Middle Adults the highest frequency observed was also in the lumbar region $(2 / 8,25 \%)$, but the region with the second highest frequency was in the cervical joints $(3 / 23,13 \%)$. There was a general trend of increasing frequency down the spine in Young and Middle Adults.

\section{Osteoarthritis}

In regards to osteoarthritis presenting in the population sample, $21 \%(6 / 29)$ of individuals and $7 \%(11 / 164)$ of joints exhibited osteoarthritis. The cervical region had the highest frequency of osteoarthritis as $12 \%$ of cervical joints (8/67) exhibited osteoarthritis. The lumbar region in this sample exhibited no osteoarthritis. One individual (Old adult male) was observed with eburnation in their cervical joints (C3/4-C4/5). Five other individuals (two young adult males, one young adult female, and two middle adult females) were observed to have porosity on the apophyseal joints but as there was no osteophytosis or eburnation observed in the joint, osteoarthritis could not be identified.

There was almost a significant difference between frequency of osteoarthritis in males and females $(\mathrm{p}=.0638)$, however, frequency of osteoarthritis within the joints of males and females was not significantly different (table 3 ). 44\% (4/9) of females in the sample exhibited osteoarthritis while $9 \%(6 / 65)$ of their joints were affected (figure 9). Females only exhibited osteoarthritis in the cervical region (22\%, $5 / 23$ joints). Males exhibited osteoarthritis in $11 \%$ $(2 / 19)$ of individuals and 5\% (5/100) of joints. Osteoarthritis within Albany males was observed not in the lumbar region, but in both cervical ( $7 \%, 3 / 43$ joints) and thoracic regions $(6 \%, 2 / 33$ joints). 


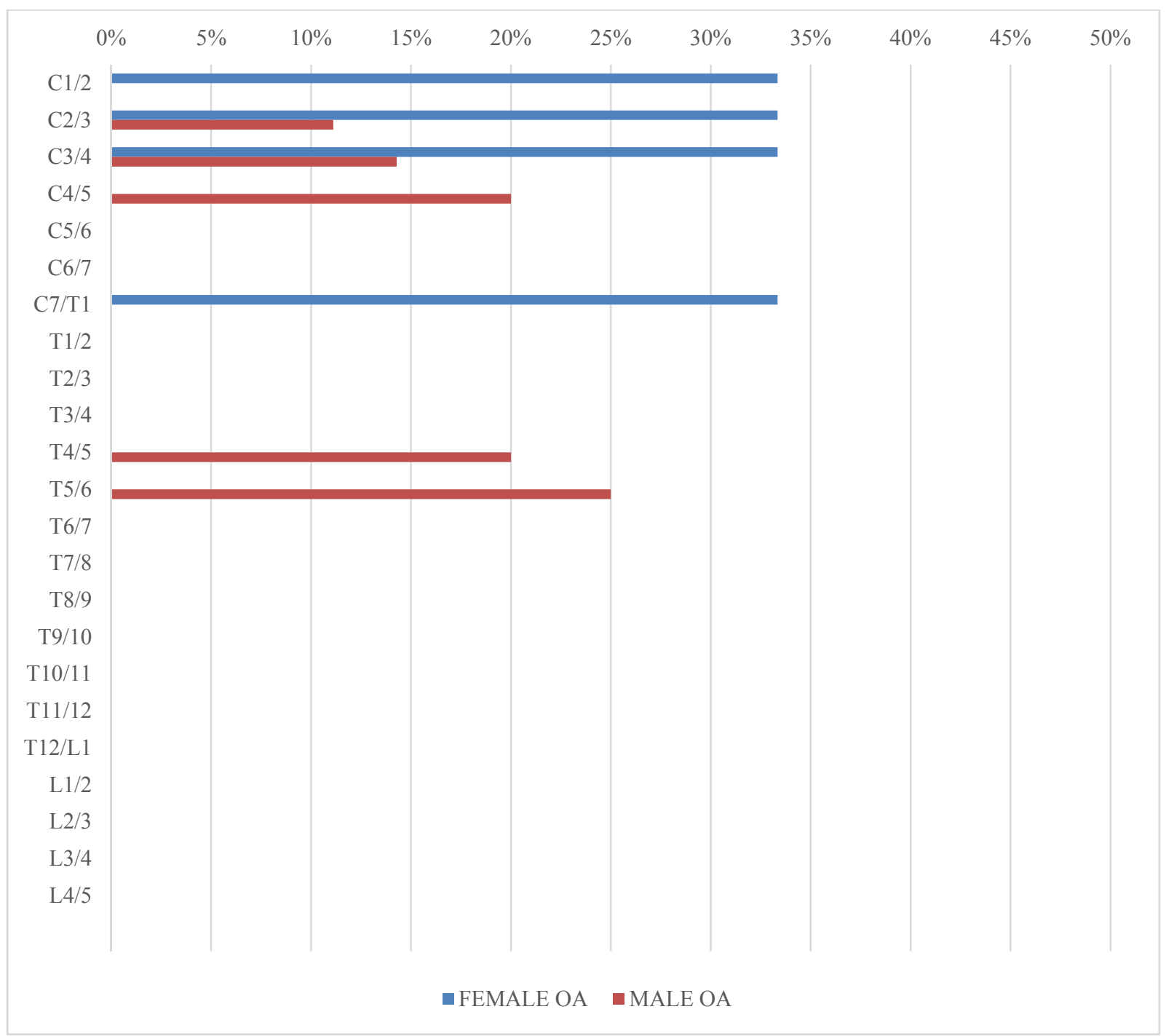

Figure 9. Albany Mounds osteoarthritis distribution comparing sex

There was statistical significance between frequencies of joints in Young and Middle

Adults as well as between joints in Young and Old Adults exhibiting osteoarthritis (table 4).

Middle Adults had the highest frequency of individuals with osteoarthritis as $50 \%(4 / 8)$ of

Middle Adults exhibited osteoarthritis and 14\% (7/49) of their joints were affected. Osteoarthritis observed in the thoracic region was only associated with the Middle Adult category as the rest of the arthrosis was restricted to the cervical region and the C7/T1 joints for Young and Old Adults. Highest frequency of osteoarthritis within all age categories was observed in the cervical region. 
There was a general decreasing trend of osteoarthritis down the spine for Young and Middle Adults.

\section{Kuhlman Mounds}

Kuhlman Mounds had 43 adults that met the criteria for this research. From that sample size, 27 individuals were observed to have at least one arthrosis in the spine. Table 5 lists the frequency and prevalence of Schmorl's node, osteophytosis, and osteoarthritis observations in individuals in the sample.

Table 5. Frequency Data for Kuhlman Mounds Site

\begin{tabular}{|c|c|c|c|c|}
\hline & \multicolumn{3}{|c|}{ Age } & \multirow[b]{2}{*}{ Overall Total } \\
\hline & Young Adult & Middle Adult & Old Adult & \\
\hline Sample adults & 24 & 12 & 7 & 43 \\
\hline $8=$ Total indv. with Schmorl's nodes & & & & $19 \%$ \\
\hline Male & $1(8 \%)$ & $1(17 \%)$ & $2(50 \%)$ & 4 \\
\hline Female & $2(18 \%)$ & $1(40 \%)$ & $1(33 \%)$ & 4 \\
\hline Unknown & 0 & 0 & & 0 \\
\hline $18=$ Total indv. with Osteophytosis & & & & $42 \%$ \\
\hline Male & $2(17 \%)$ & $4(67 \%)$ & $3(75 \%)$ & 9 \\
\hline Female & $5(45 \%)$ & $2(20 \%)$ & $1(33 \%)$ & 8 \\
\hline Unknown & 0 & $1(50 \%)$ & & 1 \\
\hline $9=$ Total indv. with Osteoarthritis & & & & $21 \%$ \\
\hline Male & $2(17 \%)$ & $2(33 \%)$ & $2(50 \%)$ & 6 \\
\hline Female & $1(9 \%)$ & $1(20 \%)$ & 0 & 2 \\
\hline Unknown & 0 & $1(50 \%)$ & & 1 \\
\hline
\end{tabular}




\section{Schmorl's Nodes}

Schmorl's nodes were observed in 19\% (8/43) of individuals and in 5\% (22/420) of joints in the Kuhlman Mounds sample. In terms of frequency patterning, Schmorl's nodes within this sample had the highest frequency in the lumbar region $(13 \%, 12 / 96$ joints) with the thoracic region closely behind in second highest frequency $(5 \%, 8 / 163$ joints) (figure 10$)$. The cervical region had the lowest as no Schmorl's nodes were observed in the region. 


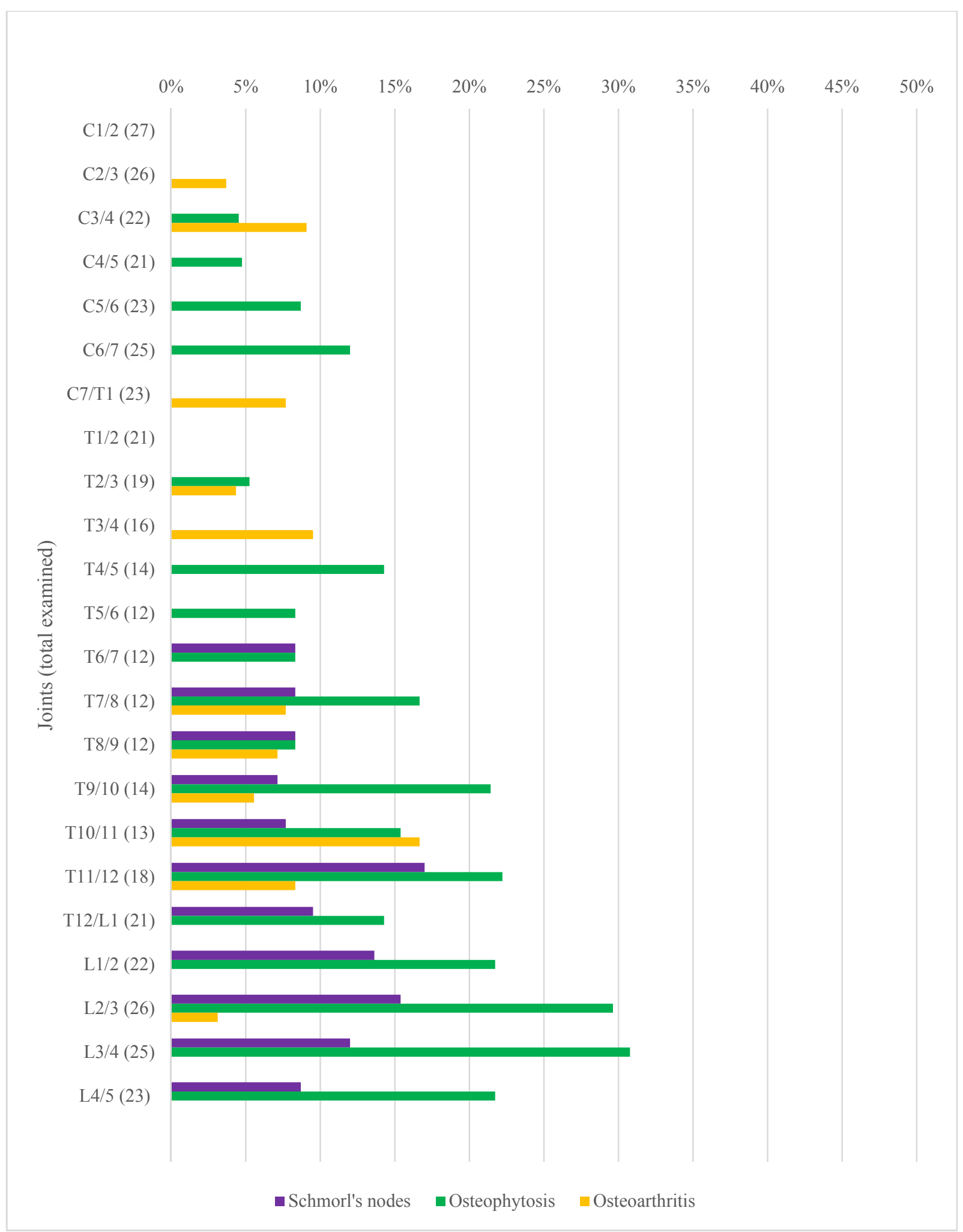

Figure 10. Kuhlman Mounds arthroses distribution 
There was no statistical difference $(\mathrm{p}<.05)$ for individual males and females with Schmorl's nodes, nor for joints in males and females (Table 5). Females in this sample exhibited Schmorl's nodes in 21\% (4/19) of individuals and 6\% (13/220) of joints (figure 11). Highest frequency of Schmorl's nodes for females was in the lumbar region (13\%, 6/46 joints). Males also exhibited Schmorl's nodes most frequently in the lumbar region (14\%, 7/49 joints). Males exhibited Schmorl's nodes in $18 \%(4 / 22)$ of individuals and in $5 \%(9 / 185)$ joints within the sample.

Table 6. Fisher's Exact P-values Comparing Sex

\begin{tabular}{|lll|}
\hline Kuhlman Mounds & Fisher's exact - individuals & Fisher's exact - arthroses \\
\hline Schmorl's nodes & 1.0000 & 0.6630 \\
Osteophytosis & 1.0000 & $0.0001^{*}$ \\
Osteoarthritis & 0.2488 & 1.0000 \\
\hline
\end{tabular}

Note: * indicates significance $(p<.05)$ 


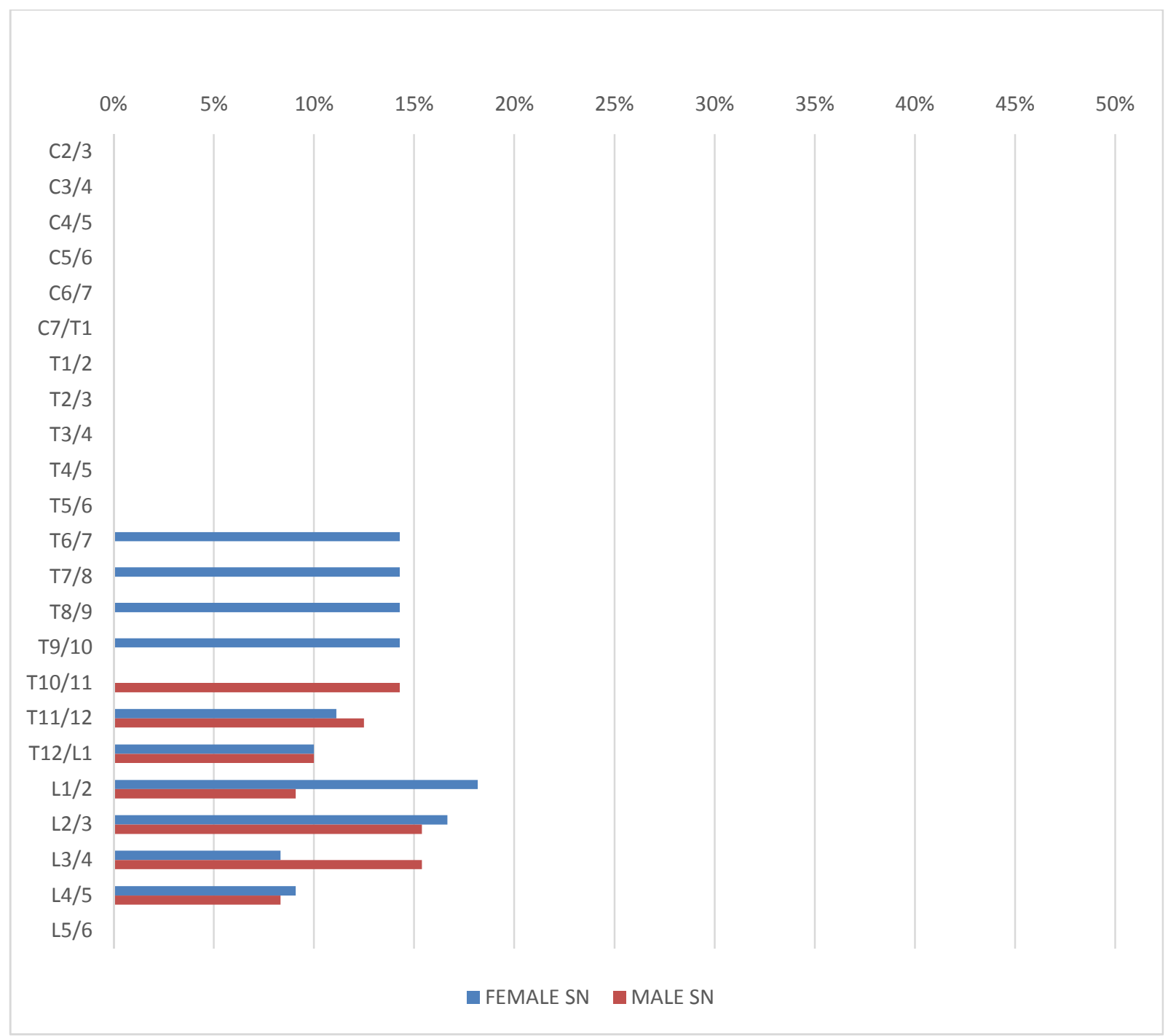

Figure 11. Kuhlman Mounds Schmorl's node distribution comparing sex

There was no statistical significance between any of the frequencies of joints exhibiting Schmorl's nodes in the age groups (table 7). Frequencies of joints exhibiting Schmorl's nodes in Middle and Old Adults were almost significantly different $(\mathrm{p}=.0518)$. Old Adults at Kuhlman Mounds were the were the most affected by Schmorl's nodes as 43\% (3/7 individuals) in the category exhibited at least one Schmorl's node in their spine. Within the Young Adult category of Albany Mounds, Schmorl's nodes were observed the most frequently in the lumbar region $(16 \%, 8 / 50$ joints). The thoracic region had a frequency of $3 \%$ (2/76 joints). Similarly, Old Adults in this sample also showed the highest frequency in the lumbar region (27\%, 4/15 joints). 
There was no observation of Schmorl's nodes in the lumbar region for the Middle Adults.

Highest frequency for the age category was in the thoracic region $(5 \%, 3 / 55$ joints $)$. There was a general trend of increasing pathology frequency down the spine for Young, Middle, and Old Adults.

Table 7. Fisher's Exact P-values Comparing Age

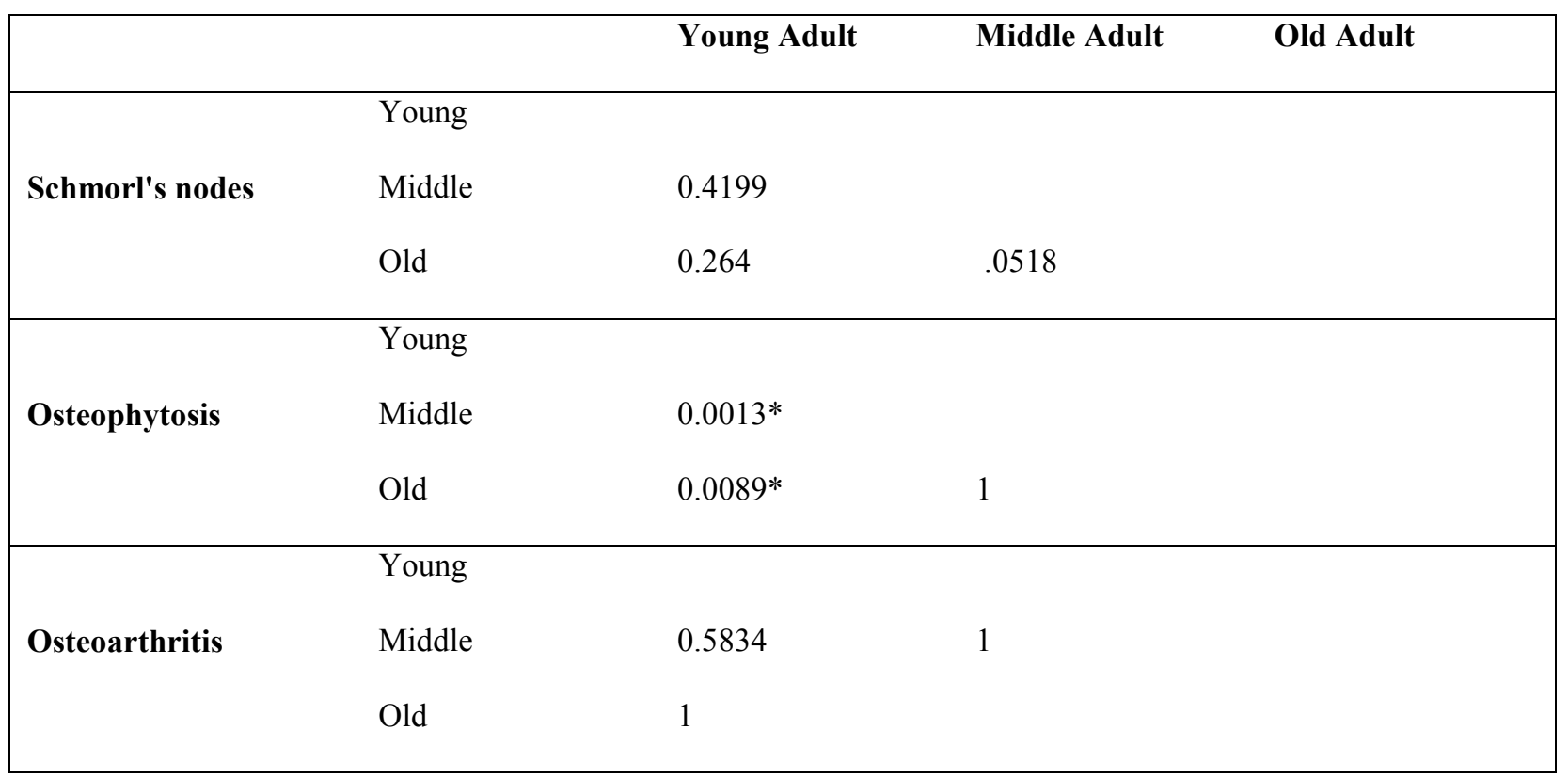

Note: * indicates significance $(p<.05)$

\section{Osteophytosis}

Osteophytosis was observed in $42 \%$ of individuals examined (18/43 individuals) and $12 \%$ of joints examined (53/453 joints). Osteophytosis had the highest frequency within the lumbar region $(26 \%, 26 / 99$ joints $)$ and the lowest frequency in the cervical region $(5 \%, 7 / 144$ joints) (figure 10). There were 23 joints that exhibited severe cases of osteophytosis with a score of 2 or 3 , which were located in 12 individuals.

There was no significant difference between frequency in males and females with observed osteophytosis $(\mathrm{p}=1.000)$, but there was a significant difference between frequency of joints with observed osteoarthritis in males and females ( $p=.0001)$ (Table 6). 42\% (8/19) of 
females exhibited osteophytosis and 7\% of their joints (16/238) were affected (figure 12).

Highest frequency of osteophytosis was observed in the lumbar region $(17 \%, 8 / 47)$. Males also had the highest frequency in the lumbar region $(37 \%, 18 / 49)$ and there is a trend of increasing arthrosis frequency down the spine for both sexes. 41\% (9/22) of males exhibited osteophytosis and $17 \%$ of their joints $(34 / 205)$ were affected.

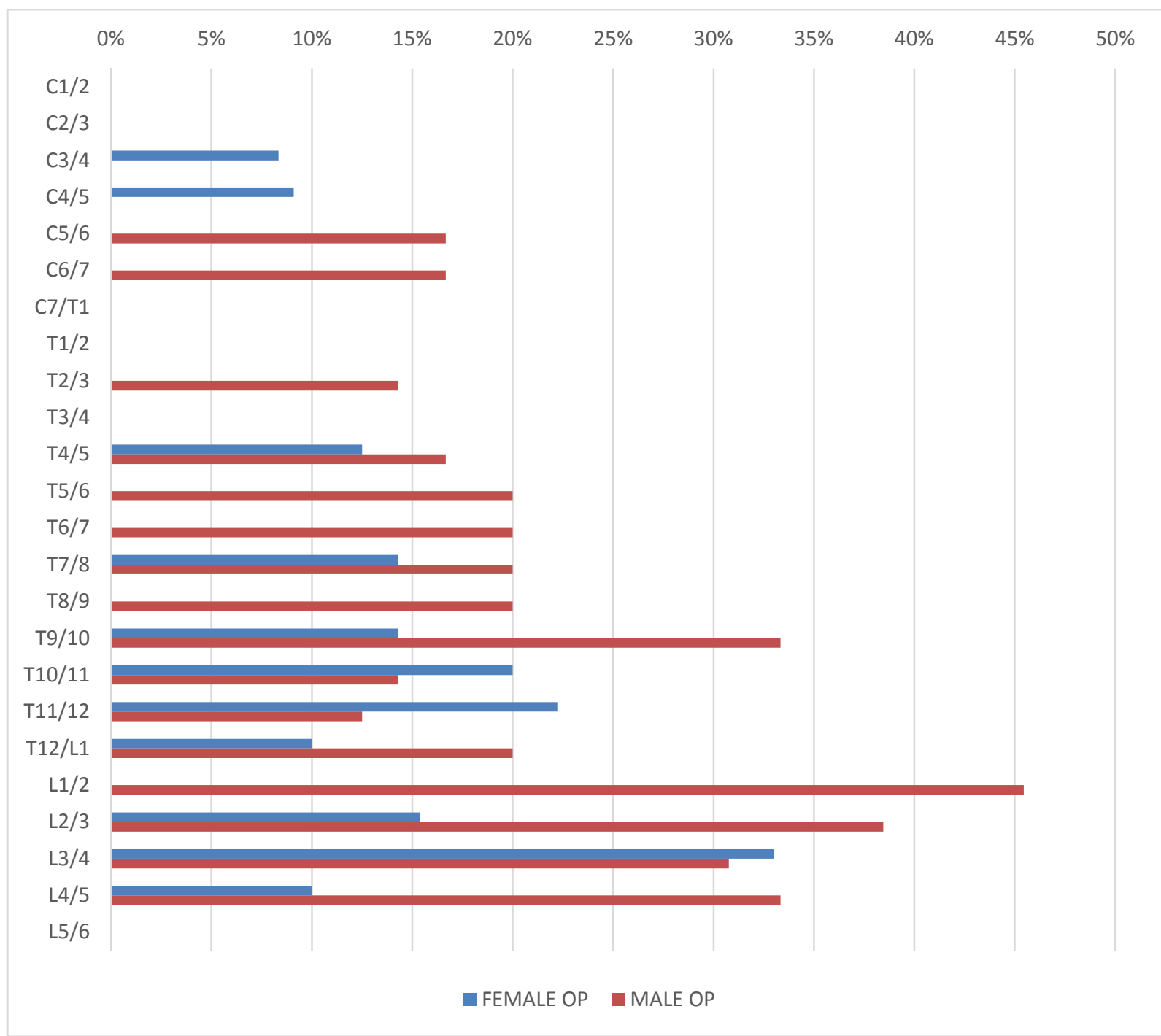

Figure 12. Kuhlman Mounds osteophytosis distribution comparing sex

There was statistical significance between frequencies of joints in Young and Middle Adults as well as Young and Old Adults exhibiting osteophytosis (table 7). Middle Adults exhibited the highest frequency of individuals with osteophytosis (58\%, 7/12 individuals). 
Osteophytosis had the highest observed frequency in the lumbar region (14\%, 7/50 joints) in Young Adults, Middle Adults (26\%, $8 / 31$ joints), and Old Adults (67\%, 10/15 joints) with the thoracic region having the second highest frequency. There was a general trend of increasing frequency down the spine in Young and Middle Adults.

\section{Osteoarthritis}

In regards to osteoarthritis presenting in the population sample, $21 \%(9 / 43)$ of individuals (table 3) and 3\% (17/529) of joints exhibited osteoarthritis. The thoracic region had the highest frequency of osteoarthritis as 5\% of thoracic joints (11/206) exhibited osteoarthritis (figure 10). The lumbar region in this sample exhibited no osteoarthritis. No instances of eburnation were observed within the Kuhlman Mounds sample, however, there were 7 individuals that presented with porosity, but no other indication of osteoarthritis on the apophyseal joints. One individual presented with 7 observations of osteoarthritis, mainly concentrating in the lower thoracic joints.

There was no significant difference between frequency of males and females with observed osteoarthritis $(\mathrm{p}=.2488)$ nor was there any significant difference between the frequency of joints with observed osteoarthritis in males and females $(p=1.000)($ table 6$) .11 \%(2 / 19)$ of females in the sample exhibited osteoarthritis while 3\% $(8 / 262)$ of their joints were affected (figure 13). Females had highest frequency of osteoarthritis in the thoracic region $(6 \%, 7 / 108$ joints). Males exhibited osteoarthritis in 27\% (6/22) of individuals and 3\% (8/247) of joints. Osteoarthritis within Kuhlman males was observed equally frequent in the cervical (2/66 joints) and lumbar (2/63 joints) at 3\%. 


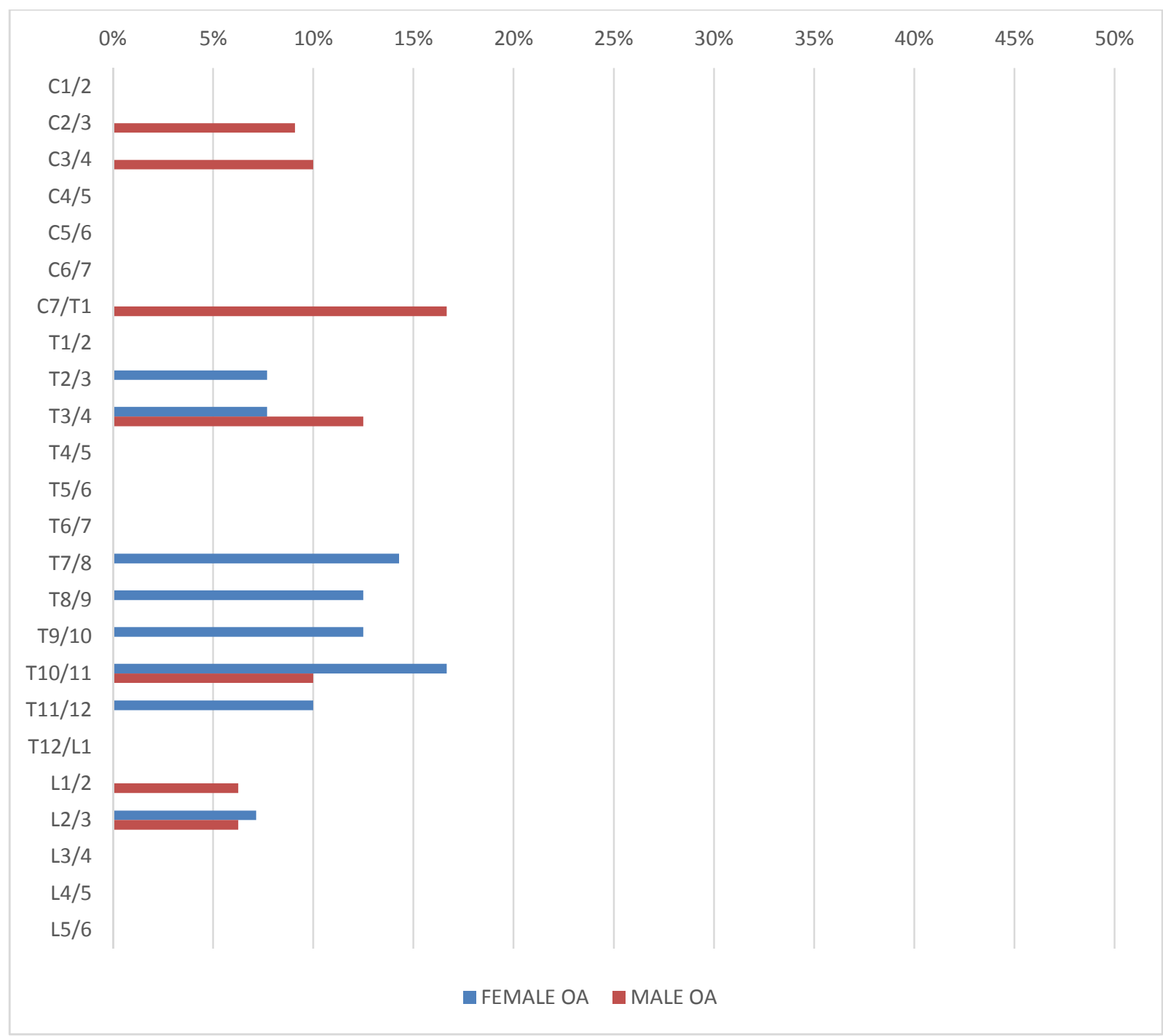

Figure 13. Kuhlman Mounds osteoarthritis distribution comparing sex

There was no statistical significance between any of the frequencies of joints exhibiting osteoarthritis in the age groups (table 7). Middle Adults had the highest frequency of individuals with osteoarthritis as 33\% (4/12) of Middle Adults exhibited osteoarthritis, but only 2\% (4/161) of their joints were affected. Young Adults in this sample had more frequently observed joints with osteoarthritis $(4 \%, 10 / 269)$. Thoracic osteoarthritis was the most frequent for Young Adults $(6 \%, 7 / 108$ joints $)$ and Old Adults $(3 \%, 1 / 29)$ joints $)$. Only Middle Adults had osteoarthritis most frequently observed in the cervical region, while the other categories had no cervical 
osteoarthritis observations. There was a general decreasing trend of osteoarthritis down the spine for Young Adults while the other two categories showed no patterning.

\section{Dickson Mounds}

The Dickson Mounds population sample was the largest due to the amount of available skeletal material as well as the preservation of the remains. At least one arthrosis was observed in the spines of 39 out of the 52 total adult spines observed within the population sample of Dickson Mounds. Results for the presence and frequency of arthroses within the population sample are provided in table 8 .

Table 8. Frequency Data for Dickson Mounds Site

\begin{tabular}{|c|c|c|c|c|}
\hline & \multicolumn{3}{|c|}{ Age } & \multirow[b]{2}{*}{ Overall Total } \\
\hline & Young Adult & Middle Adult & Old Adult & \\
\hline Sample adults & 23 & 24 & 5 & 52 \\
\hline $19=$ Total indv. with Schmorl's nodes & & & & $37 \%$ \\
\hline Male & $4(33 \%)$ & $5(31 \%)$ & $1(50 \%)$ & 10 \\
\hline Female & $5(45 \%)$ & $3(38 \%)$ & $1(33 \%)$ & 9 \\
\hline Unknown & & & & \\
\hline $22=$ Total indv. with Osteophytosis & & & & $42 \%$ \\
\hline Male & 0 & $14(88 \%)$ & $1(50 \%)$ & 15 \\
\hline Female & 0 & $4(50 \%)$ & $3(100 \%)$ & 7 \\
\hline Unknown & & & & \\
\hline $12=$ Total indv. with Osteoarthritis & & & & $23 \%$ \\
\hline Male & 0 & $7(44 \%)$ & $1(50 \%)$ & 8 \\
\hline Female & $2(18 \%)$ & $1(33 \%)$ & $1(33 \%)$ & 4 \\
\hline Unknown & & & & \\
\hline
\end{tabular}




\section{Schmorl's Nodes}

Schmorl's nodes were observed in 37\% (19/52) of individuals and in 5\% (54/1032) of joints in the Dickson Mounds sample. In terms of frequency patterning, Schmorl's nodes within this sample had the highest frequency in the lumbar region $(11 \%, 23 / 205$ joints $)$ with the thoracic region closely behind in second highest frequency $(5 \%, 26 / 516$ joints) (figure 14$)$. The cervical region had the lowest as no Schmorl's nodes were observed in the region. 


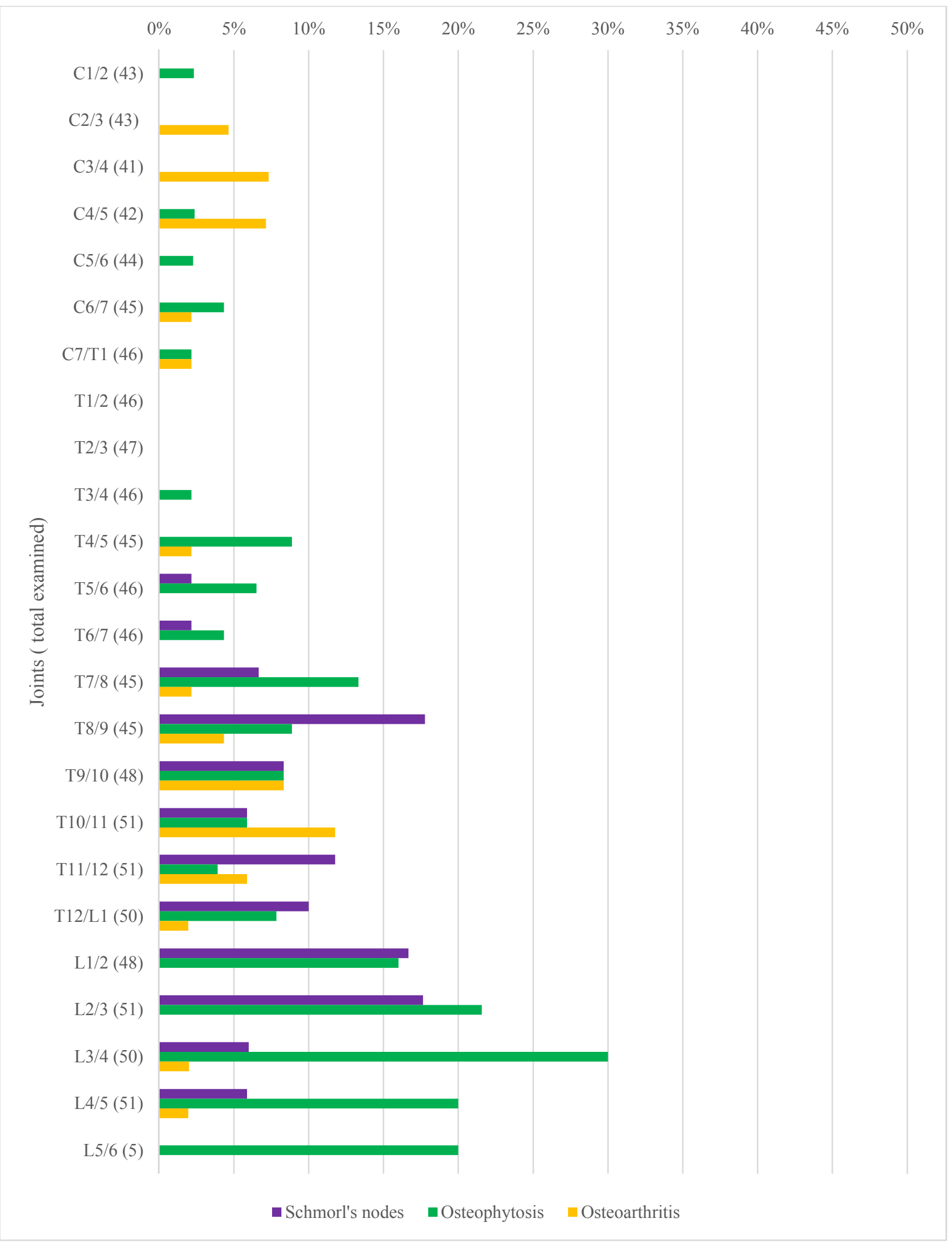

Figure 14. Dickson Mounds arthroses distribution 
There was no statistical difference $(\mathrm{p}<.05)$ for individual males and females with Schmorl's nodes nor for joints in males and females (Table 9). Females in this sample exhibited Schmorl's nodes in 39\% (9/23) (table 6) of individuals and 4\% (20/445) of joints (figure 15). Highest frequency of Schmorl's nodes for females was in the lumbar region (12\%, 10/86 joints). Males also exhibited Schmorl's nodes most frequently in the lumbar region (11\%, 13/119 joints). Males exhibited Schmorl's nodes in 34\% (10/29) of individuals and in 4\% (27/608) joints within the sample.

Table 9. Fisher's Exact P-values Comparing Sex

\begin{tabular}{|lll|}
\hline Dickson Mounds & Fisher's exact - individuals & Fisher's exact - arthroses \\
\hline Schmorl's nodes & 0.7778 & 0.2010 \\
Osteophytosis & 0.1620 & $0.0004^{*}$ \\
Osteoarthritis & 0.7519 & 0.0587 \\
\hline
\end{tabular}

Note: $*$ indicates significance $(p<.05)$ 


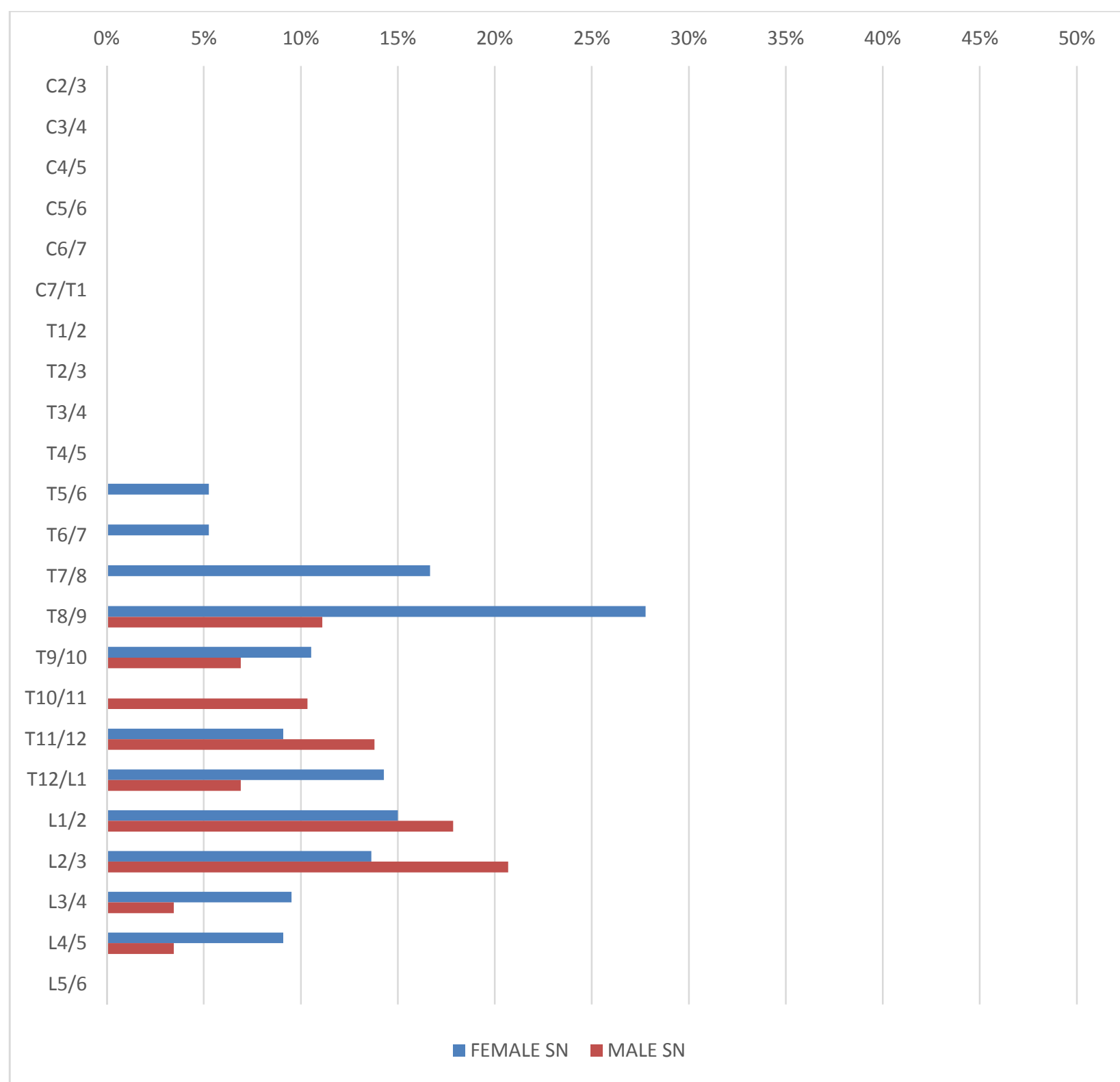

Figure 15. Dickson Mounds Schmorl's node distribution comparing sex

There was no statistical significance between any of the frequencies of joints exhibiting Schmorl's nodes in the age groups (table 10). Old Adults at Kuhlman Mounds were the were the most affected by Schmorl's nodes as 40\% (2/5 individuals) in the category exhibited at least one Schmorl's node in their spine. Within the Young Adult category of Albany Mounds, Schmorl's nodes were observed the most frequently in the lumbar region $(10 \%, 9 / 91$ joints $)$. The thoracic region had a frequency of 5\% (13/238 joints). Similarly, Middle Adults in this sample also 
showed the highest frequency in the lumbar region (14\%, 13/96 joints) while the thoracic region had a frequency of $4 \%$ ( $9 / 243$ joints). Old Adults had a higher frequency in the thoracic region $(11 \%, 4 / 35$ joints), while the lumbar region in Old Adults had a frequency of $6 \%$ (1/18 joints). Highest frequency for the age category was in the thoracic region ( $5 \%, 3 / 55$ joints). There was a general trend of increasing arthrosis frequency down the spine for Young and Middle Adults, but a trend of decreasing arthrosis frequency in Old Adults.

Table 10. Fisher's Exact P-values Comparing Age

\begin{tabular}{|c|c|c|c|c|}
\hline & & Young Adult & Middle Adult & Old Adult \\
\hline \multirow{3}{*}{ Schmorl's nodes } & Young & & & \\
\hline & Middle & 1 & & \\
\hline & Old & 0.2899 & 0.4143 & \\
\hline \multirow{3}{*}{ Osteophytosis } & Young & & & \\
\hline & Middle & $0.0001^{*}$ & & \\
\hline & Old & $0.0001^{*}$ & $0.0014 *$ & \\
\hline \multirow{3}{*}{ Osteoarthritis } & Young & & & \\
\hline & Middle & $0.0001 *$ & & \\
\hline & Old & $0.0001 *$ & $0.0457 *$ & \\
\hline
\end{tabular}

Note: $*$ indicates significance $(p<.05)$

\section{Osteophytosis}

Osteophytosis was observed in $42 \%$ of individuals examined (22/52 individuals) and $8 \%$ of joints examined (84/1078 joints). Osteophytosis had the highest frequency within the lumbar region $(22 \%, 45 / 206$ joints) and the lowest frequency in the cervical region ( $2 \%, 5 / 259$ joints) (figure 14). There were 50 joints that exhibited severe cases of osteophytosis with a score of 2 or 3, which were located in 14 individuals. 
There was no significant difference between frequency in males and females with observed osteophytosis $(\mathrm{p}=.1620)$, but there was a significant difference between frequency of joints with observed osteophytosis in males and females $(\mathrm{p}=.0004)$ (table 9$) .30 \%(7 / 23)$ of females exhibited osteophytosis and 4\% of their joints (20/445) were affected (figure 16). Highest frequency of osteophytosis was observed in the lumbar region (14\%, 12/88 joints). The thoracic region had a frequency of $3 \%(7 / 211)$, but there were no observations of osteophytosis in the cervical region of females. Males in the Dickson Mound sample also had the highest frequency of osteophytosis observed in the lumbar region ( $28 \%, 33 / 118$ joints). The thoracic region had a frequency of $8 \%$ (24/305 joints) and the cervical region had the lowest frequency of $3 \%(5 / 154) .52 \%(15 / 29)$ of males exhibited osteophytosis and $10 \%$ of their joints $(66 / 633)$ were affected. 


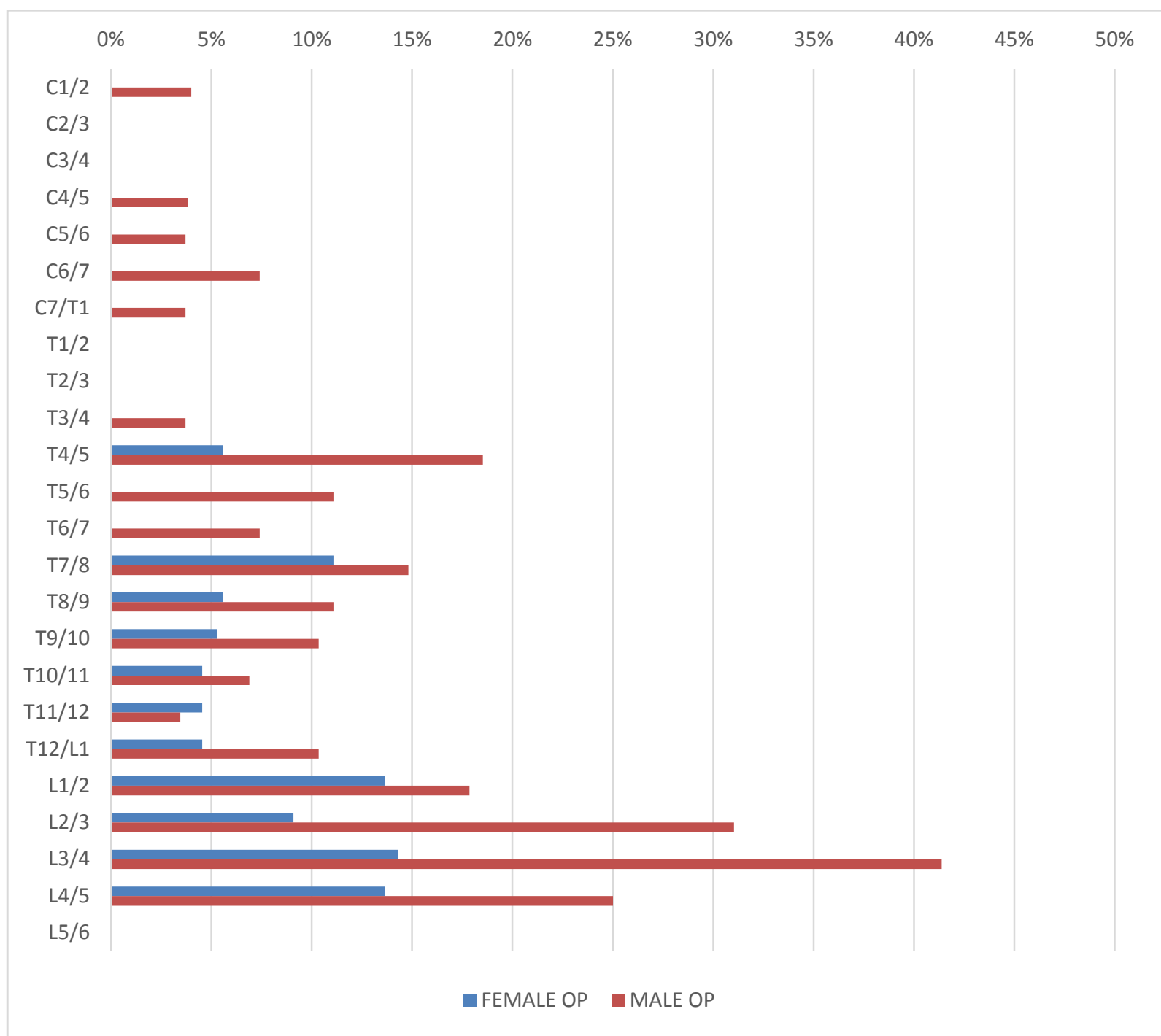

Figure 16. Dickson Mounds osteophytosis distribution comparing sex

There was statistical significance between all age group frequencies of joints exhibiting osteophytosis (table 10). Middle Adults exhibited the highest frequency of individuals with osteophytosis (75\%, 18/24 individuals). Osteophytosis had the highest observed frequency in the lumbar region in Middle Adults (44\%, $43 / 97$ joints) and Old Adults (35\%, 6/17 joints), but no observations of osteophytosis in Young Adults at all. There was a general trend of increasing frequency down the spine in Middle and Old Adults. 


\section{Osteoarthritis}

In regards to osteoarthritis presenting in the population sample, $23 \%(12 / 52)$ of individuals and 3\% (29/1082) of joints exhibited osteoarthritis. The cervical and thoracic region had the highest frequency of osteoarthritis as 3\% of cervical joints $(9 / 259)$ exhibited osteoarthritis and 3\% of thoracic joints (16/519) exhibited osteoarthritis (figure 14). The lumbar region in this sample had a frequency of $1 \%$ (2/207 joints) of observed osteoarthritis. There were 3 observations of joints with eburnation, all located in middle adult individuals.

There was no significant difference between frequency of males and females with observed osteoarthritis $(\mathrm{p}=.7519)$, but there was almost a significant difference between the frequency of joints with observed osteoarthritis in males and females $(\mathrm{p}=.0587)($ table 9$) .22 \%$ $(5 / 23)$ of females in the sample exhibited osteoarthritis while $2 \%(7 / 449)$ of their joints were affected (figure 17). Females had highest frequency of osteoarthritis in the thoracic region (2\%, 4/19 joints). Males exhibited osteoarthritis in 28\% (8/29) of individuals and 4\% (23/633) of joints. Osteoarthritis within Kuhlman males was observed most frequently in the cervical region $(5 \%, 8 / 154$ joints $)$ and had the second highest frequency in the thoracic region $(4 \%, 13 / 304$ joints). 


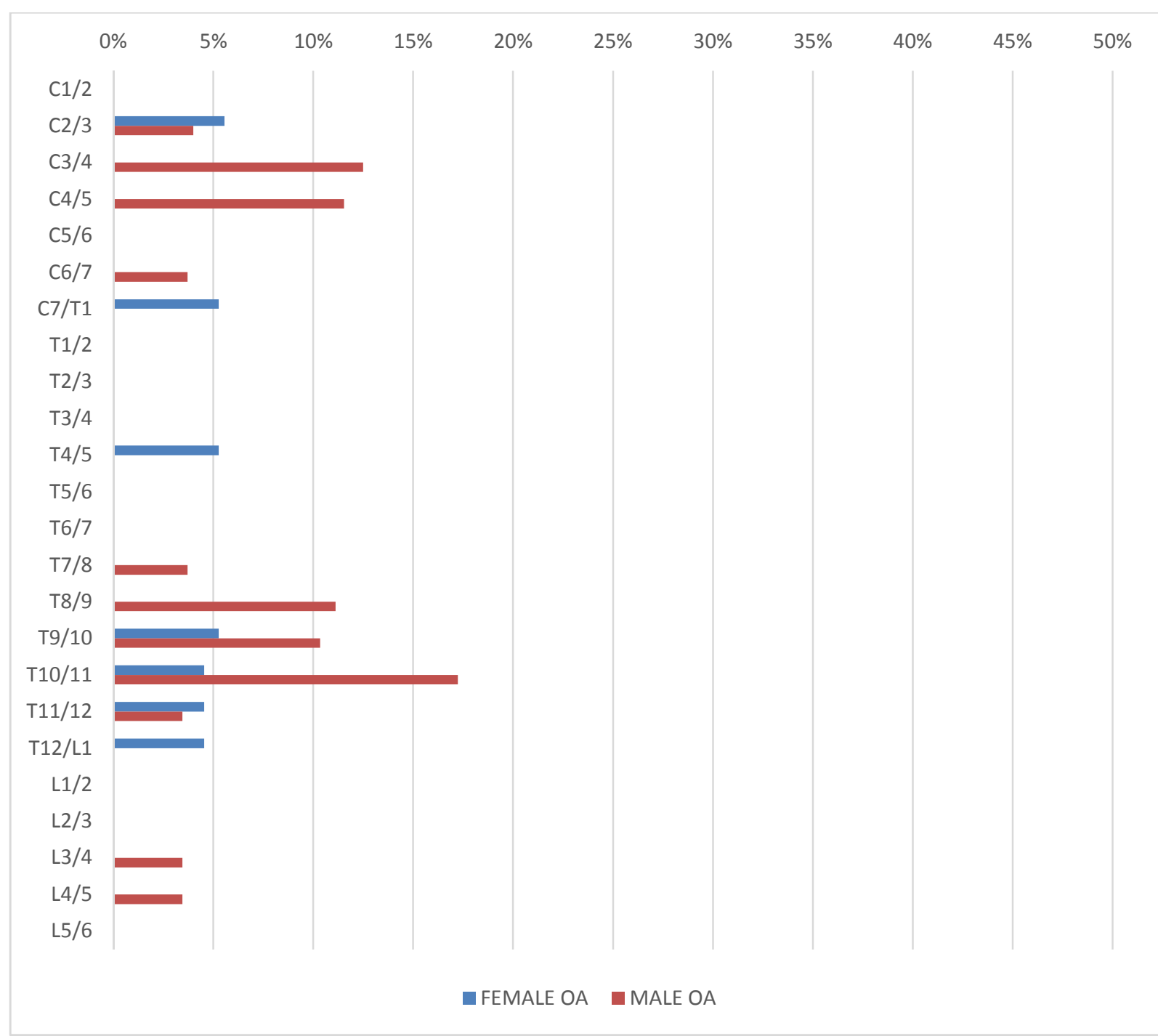

Figure 17. Dickson Mounds osteoarthritis distribution comparing sex

There was statistical significance between all age group frequencies of joints exhibiting osteoarthritis (table 10). Old Adults had the highest frequency of individuals with osteoarthritis as $40 \%(2 / 5)$ of Old Adults exhibited osteoarthritis and 10\% (8/82) of their joints were affected. Young Adults had such low observations of osteoarthritis that only the cervical region had a frequency of $1 \%$ (1/129 joints). Cervical osteoarthritis was the most frequent for Middle Adults $(6 \%, 7 / 110$ joints) while Old Adults had a higher frequency of osteoarthritis in the thoracic $(11 \%, 4 / 35$ joints $)$ and lumbar regions $(11 \%, 2 / 18)$. There was a general decreasing trend of 
osteoarthritis down the spine for Young and Middle Adults, while Old Adults had an increase and stabilization of osteoarthritis frequency down the spine.

\section{Co-occurrence}

There were no observations of arthroses occurring within the same joint, but there were four individuals who had all three arthroses observed in their spine. Within the spines of these individuals, there was one individual in the Kuhlman Mounds sample, while all others were found within the Dickson Mounds sample. The individual in Kuhlman Mounds (KLM 15) had a Schmorl's node and osteophytosis occurring on both the L2/3 and L3/4 joints. Porosity was also observed on these two joints, but osteoarthritis could not be identified. Of the individuals in Dickson Mounds, two had joints with two observed arthroses. The L2/3 joint of B. 482 had a Schmorl's node and osteophytosis observed, and the L1/2 and L2/3 of B. 267 also had Schmorl's nodes and osteophytosis observed.

There were more individuals with two arthroses observed within their spines. In total, twenty three individuals exhibited two arthroses; four from Albany Mounds (three middle adult females and one young adult male), ten from Kuhlman Mounds (three young adult females, one young adult male, one middle adult female, one middle adult male, one old adult female, two old adult males, and one unknown middle adult), and nine from Dickson Mounds (two middle adult females, four middle adult males, two old adult females, and one adult male). Of those individuals, $56.5 \%(13 / 23)$ had at least one joint with two co-occurring arthroses.

\section{Site Differences}

Overall, the highest frequency of Schmorl's nodes by joint was observed equally in Kuhlman and Dickson Mounds (5\%,22/420 and 54/1032 respectively), while osteophytosis was observed the most frequently within the Kuhlman Mounds sample (12\%, 53/453), and 
osteoarthritis was most frequently observed in Albany Mounds (7\%, 11/164). Dickson Mounds had the highest frequency of individuals affected by all pathologies, which was significant in comparison to individuals with Schmorl's nodes in Albany Mounds (Table 8).

Table 11. Fisher's Exact P-values Comparing Individuals in Each Site

\begin{tabular}{|lccc|}
\hline Schmorl's nodes & Albany Mounds & Kuhlman Mounds & Dickson Mounds \\
Dickson Mounds & $.0176^{*}$ & .6743 & \\
Kuhlman Mounds & .5702 & & \\
Albany Mounds & & & \\
\hline Osteophytosis & Albany Mounds & Kuhlman Mounds & Dickson Mounds \\
Dickson Mounds & .1472 & 1.000 & \\
Kuhlman Mounds & .1386 & & \\
Albany Mounds & & & Dickson Mounds \\
\hline Osteoarthritis & 1.000 & & \\
Dickson Mounds & 1.000 & & \\
Kuhlman Mounds & & & \\
Albany Mounds & & & \\
\hline
\end{tabular}

Note: * indicates significance $(p<.05)$ 


\section{CHAPTER V: DISCUSSION AND CONCLUSION}

This research sought to answer if there was a co-occurrence among the three arthroses, Schmorl's nodes, osteophytosis, and osteoarthritis in the spine. There was no joint in which all three arthroses were observed across the samples. There were however, Schmorl's nodes and osteophytosis occurring in the same joint and in some of those joints, porosity on the apophyseal facets was observed. Because the methodological approach in identifying osteoarthritis required at least two pathologies to be observed within a joint, this porosity could not be identified as osteoarthritis. If a different approach in identifying osteoarthritis was taken, perhaps there would be some joints exhibiting all three arthroses, but the researcher stands by the presence of two pathology indicative of osteoarthritis. This is due to the belief that scoring osteoarthritis based on "moderate" or "severe" cases is not a standard way of scoring. These scores would be relative to the samples themselves and it would rely on the interpretations of researchers to all agree on what "moderate" vs. "severe" is.

As for the co-occurrence of Schmorl's nodes and osteophytosis, this could be evidence for an association between the two, however, both occur independent of one another as well. Thus, more research would be needed in order to establish patterns on co-occurrence in order to determine if this could be significant enough to call an association. Different patterns seemed to emerge from the data, but again, further studies including individuals in sites with similar time periods or at the very least similar subsistence strategies would need to be examined.

\section{Differences between Sexes}

In the examination of pattern differences between sexes within each sample some patterns were consistent across samples. For instance, Schmorl's nodes had the highest frequency 
within the lumbar region of the spine in all three of the sites and within both males and females. There were however, also instances of pattern differences between sexes within each site.

Females from Albany Mounds exhibited higher frequencies of osteophytosis and osteoarthritis than females from the other two sites, and neither males nor females from the Albany Mounds sample exhibited osteoarthritis in the lumbar. This could suggest that less loadbearing stress attributing to lumbar arthroses were affecting the people of Albany Mounds and perhaps a longer lifespan of females in Albany than the other two sites (Novak 2011). The high frequency of osteophytosis overall in females was significant when compared to Dickson Mounds females $(\mathrm{p}=.0354)$. This was surprising as the research hypothesized an increase in the reactive pathology with the introduction to intensive agriculture. One explanation for this could be that osteophytosis in the spine is not as associated with mechanical stress as previously thought, but more reactive to the aging process of the spine.

The statistical significance of osteophytosis frequency found between males and females within the Albany Mounds sample could have been due to the large discrepancy between the sample size of males and females. However, if the significance was still observed in a larger Middle Woodland population, this could be evidence of burden bearing on the neck for women, which could be supported by the patterning of Schmorl's nodes and osteoarthritis in the females as well. The significance in females with osteoarthritis compared to males, but the lack of significance in frequency of osteoarthritis in males and females, suggests that the females observed with osteoarthritis may not be representative of the entire population.

While no frequency of males and females exhibiting any pathology at Kuhlman Mounds is significantly different, there is a significantly higher frequency of osteophytosis in males than in females. 
There was no significant difference between frequency of males and females in the Dickson Mounds sample, however, the significance in osteophytosis and osteoarthritis frequency between males and females suggests the two may have been experiencing different forms of stress (Sofaer-Derevinski 2000). Compared to the distribution pattern, this could be evidence of a sexed-division of labor within the Dickson Mounds sample. The significantly higher frequency of pathologies in males as well as a higher frequency of males affected by pathologies is consistent with Lallo's (1973) research of the same population. Osteoarthritis within males showed a decrease from cervical to lumbar region, which differed from all other patterns observed within the Dickson Mounds sample. This could be explained by a difference in the cause to this particular sample's osteoarthritis, which could be mechanical stress related rather than age related.

Since all males have significantly higher frequencies of osteophytosis than females in all population samples, it begs the question are males more susceptible than females to forces causing osteophytosis? As a generally reactive pathology that develops to stabilize joint, it would appear that males are more likely to need extra stability within their spine.

Females in every population sample had Schmorl's node distribution higher up in the spine than their male counterparts. One suggestion for this pattern could be from pregnancy and women performing labor during their pregnancies. A way to corroborate this would be to examine medical literature and modern day samples of women for this same pattern.

\section{Differences among Age groups}

Six young adults were observed with osteoarthritis in their spines. One was observed in the Albany Mounds sample, three were observed in Kuhlman Mounds, and two individuals were observed in Dickson Mounds. One young adult female in Kuhlman Mounds had seven joints 
exhibiting osteoarthritis, five joints continuously exhibiting beginning at the $T 7 / 8$ joint through the T11/12. The osteoarthritis observed in the Young Adults of this research could have been due to trauma that caused the joints to move in an unfamiliar way creating bone on bone rubbing, but we know due to the age group that the osteoarthritis was not likely to be caused aging.

The similarity in distribution of Schmorl's nodes among age groups in Albany Mounds could have been due to the specific activities the people were engaging in that caused Schmorl's node development within one region. It also suggests that Schmorl's nodes may not be as useful in determining the amount of mechanical stress a population may have been enduring as it would have been expected for there to be a general increase in a pathology that is usually caused by mechanical stress.

Frequencies of osteoarthritis were overall higher in the Old Adult categories, but it was the smallest category among all three sites, so sample size may have affected data rather than observing higher frequencies due to age related factors. The lack of osteoarthritis in the lumbar region of Albany Mounds could be due to activity performance, but it is likely that the sampling size has more influence over the frequency pattern. With only 8 middle adults to examine for arthroses versus the 20 young adults available for examination, most osteoarthritis that was observed could be attributed to age rather than mechanical stress.

Dickson Mounds had a significantly more Young Adults exhibiting Schmorl's nodes ( $\mathrm{p}=$ .0183). Adults may have begun engaging in more strenuous activities at a younger age, or more adults may have been engaging in hard labor more frequently in Dickson Mounds than in Albany and Kuhlman.

Middle Adults within Albany Mounds had a significantly higher frequency of osteoarthritis than the Middle Adults at both Dickson and Kuhlman Mounds. This difference 
needs to be further examined and compared to other studies similar in order to determine if this is a consistent pattern. If so, then there needs to be discussion as to why Middle Adults of Middle Woodland sites would have higher frequencies of vertebral osteoarthritis than in adults of the same age category at sites cultivating maize. One explanation could be that since the Middle Adult category would contain the largest sample of adults that had been working the longest amount of time, this significant decrease in osteoarthritis could be the result of shorter lifespans within sites that are utilizing the production of maize.

\section{Differences among Sites}

Overall, Dickson Mounds had the highest frequency of individuals affected by Schmorl's nodes and osteoarthritis, however this was only significantly different when compared to individuals with Schmorl's nodes in Albany Mounds $(\mathrm{P}=.0176)$ (Table 4.1). One explanation for this could be that "social adulthood" began sooner for people at Dickson Mounds during the Middle Mississippian Period and were required to begin working sooner, thus leading to a higher risk of developing a Schmorl's node. Another explanation could be that the factors leading to Schmorl's node development were much more prevalent during the Middle Mississippian Period such as more rigorous work causing more mechanical stress or higher frequency of trauma.

The variation in sites for highest frequencies of pathologies differs from highest frequency of individuals with the same pathologies. This provides an interesting bit of data because while Dickson had more people affected, the people did not have the highest frequency of pathologies. This could have been due to people dying at a younger age at the site from stress on their health and bodies, or it could be explained by something else entirely such as the difference in sample size. There was some significance in spinal regions when osteoarthritis and osteophytosis frequency was compared between sites. The high frequency of cervical 
osteoarthritis was significantly higher in Albany Mounds than both Kuhlman and Dickson Mounds (Table 5.1). Kuhlman Mounds when compared to Dickson Mounds had a significantly higher frequency of thoracic osteophytosis $(\mathrm{p}=.0487)$. These differences could be interpreted as different stresses on the spine such as burden bearing or workload, however, more research would need to be performed in order to establish a consistent pattern between the temporal periods. 
Table 12. Fisher Exact Tests Comparing between Spinal Regions in Sites

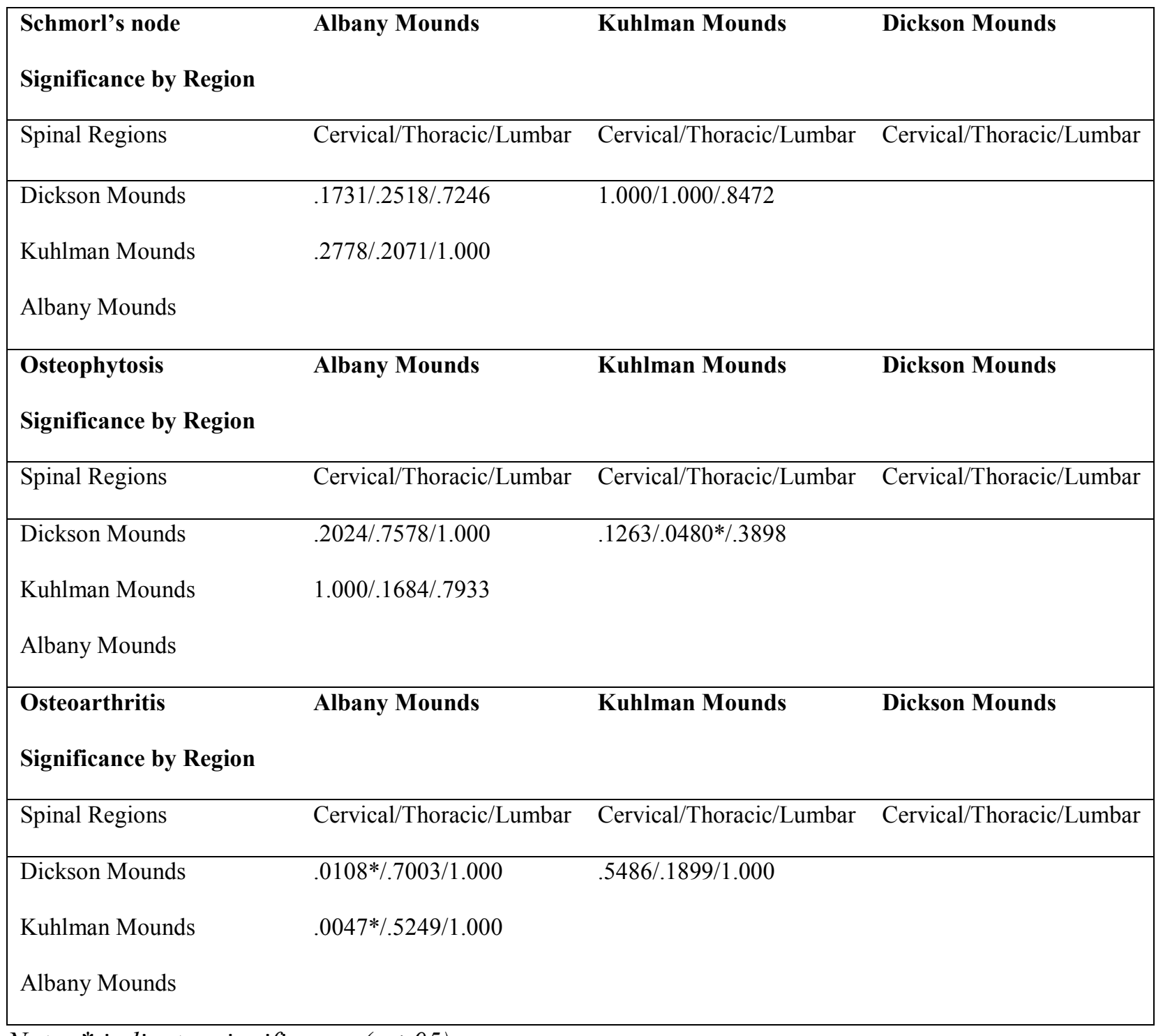

Note: * indicates significance $(p<.05)$

More severe cases of osteophytosis were observed in Dickson Mounds (5\%, 50/1078).

More severe cases of osteoarthritis were observed within the sample at Dickson Mounds as well compared to the Middle and Late Woodland sites, which supports Lallo's (1973) research of the Late Woodland and Mississippian components of Dickson Mounds. Higher frequencies of severe osteoarthritis, but lower frequencies of osteoarthritis overall at Dickson Mounds provides an 
interesting pattern of the arthroses that could suggest that osteoarthritis being observed here was not caused by aging, but by mechanical stress or trauma.

Osteophytosis was seen the most frequently within the lumbar region, which follows the same pattern Bridges (1994) found among both Archaic and Mississippian populations as well as other archaeological and clinical studies (O’Neill et al 1999; Novak \& Slaus 2001).

Osteoarthritis in the sample however was not observed to be most frequent in the lumbar region like Bridges (1994) found but varied based on the temporal site. The variability in distribution could be due to the variability in activities between sites (Sofaer-Derevinski 2000).

\section{Conclusion}

Patterns were indeed observed within each site between sexes and among age groups. Osteoarthritis and osteophytosis were observed to have different distribution patterns among sites, which was surprising as, osteoarthritis, being known to be more closely associated with aging, would be expected to have a similar pattern within each site. Schmorl's nodes however, kept a more consistent pattern throughout the sites and among sex and age categories. With that being said, osteoarthritis may give better insight into the lifestyles and activities people were engaging in than previously believed. Similarly, osteophytosis development could have also been affected by the different activities people engaged in even if those activities were not related to any sort of load-bearing. Even if the joints located where maximum curvature is likely to occur are disregarded, the frequencies observed for all arthroses throughout the samples remain the same.

The most common problem that was run into when performing the research involved the sample sizes. While it could be that with an larger sample size representing the Middle Woodland Period could result in the same frequencies, more steps should have been taken in 
order to include a sample of equal age and sex categories in order to get the best analysis. Most interpretations regarding the distribution and frequency of these vertebral pathologies is conjecture due to the inability to control for sample size. Sample size may have affected the variability in patterns of arthroses within the categories used (e.g. male, female, middle adult, etc.), however, here they show evidence that these arthroses are unlikely to be associated with one another. To gain a better understanding of the co-occurrences of Schmorl's node and osteophytosis, it would be interesting to reexamine those joints with both occurring and examine Schmorl's nodes more in depth. Looking at size and location of the Schmorl's nodes that cooccur with osteophytosis could give insight as to why they occur together and independently at different times.

Future studies could use sites with larger overall totals and encompass other aspects of the skeleton rather than focusing on the spine. Other future work could change the way spinal regions are grouped for analysis and comparison. The work here grouped the spine by region, however, the joints were maximum curvature could be separated as a comparative study that would include "transitional" joints (e.g. C7/T1 and T12/L1) and possibly examining by vertebrae rather than joint could include those joints as well. Comparing contemporaneous sites would aid in establishing a pattern of distribution and frequency as this research could only establish differences between populations with different temporalities.

Future work examining osteoarthritis's relationship with load bearing labor could include other joints such as those within the shoulder. Another place to examine in association with load bearing stress would be the spinous processes of the spine. "Kissing spine” or Baastrup's disease occurs when compression of the spine results in spinous processes resting on top of one another to produce a facet that would not normally be present (Kacki et al. 2011). Studying the should 
joints and spinous processes alongside vertebral osteoarthritis may lead to a better understanding of the relationship between osteoarthritis on the apophyseal joints and load bearing activities.

Studying pathology within the spine can be a daunting task, as it requires examination of not only multiple facets on each vertebrae, but that multiplied by the number of vertebrae present in each individual as well as a knowledge were each vertebrae is located in the column can cause any of these results to be skewed. While this all remains true, it is believed by this researcher that the spine and its pathologies cannot be ignored when interpreting activities and behaviors of a particular group of people. Further steps are required in order to maintain accuracy of pathologies and consistency in numbers of male, females, and age groups can help. 


\section{REFERENCES}

Asch, DL, KB Farnsworth, and NB Asch. 1979. Woodland subsistence and settlement in west central Illinois. in Hopewell Archaeology: The Chillicothe Conference, Ohio.

Atwell, KA. 1991. West Ridge excavations. In The Kuhlman mound group and late woodland mortuary behavior in the Mississippi River valley of west-central Illinois., eds. Karen A. Atwell, Michael D. Conner. Vol. 9, 16-96. Kampsville, Illinois: Center for American Archaeology.

Atwell, KA, and MD Conner. 1991. Introduction. In The Kuhlman mound group and Late Woodland mortuary behavior in the Mississippi River valley of west-central Illinois., eds. Karen A. Atwell, Michael D. Conner. Vol. 9, 1-6. Kampsville, Illinois: Center for American Archaeology.

Berger, TD, and E. Trinkaus. 1995. Patterns of trauma among the Neandertals. Journal of Archaeological Science 22 (6): 841-52.

Bridges, PS. 1994. Vertebral arthritis and physical activities in the prehistoric southeastern United States. American Journal of Physical Anthropology 93 (1): 83-93.

1992. Prehistoric arthritis in the Americas. Annual Review of Anthropology 21 : 67-91.

1991. Degenerative joint disease in hunter-gatherers and agriculturalists from the southeastern United States. American Journal of Physical Anthropology 85 (4): 379-91.

1989. Changes in activities with the shift to agriculture in the southeastern United States. Current Anthropology 30 (3): 385-94.

Brown, KR, P Pollintine, and MA Adams. 2008. Biomechanical implications of degenerative joint disease in the apophyseal joints of human thoracic and lumbar vertebrae. American Journal of Physical Anthropology 136 (3): 318-26. 
Buikstra, JE, and L Goldstein. 1973. The Perrins Ledge Crematory.

Buikstra, JE, and GR Milner. 1989. The Dickson Mounds site: An annotated bibliography.

Buikstra, JE, and DH Ubelaker. 1994. Standards for data collection from human skeletal remains: Proceedings of a seminar at the Field Museum of Natural History.

Burke, K. L. 2012. Schmorl's nodes in an American military population: Frequency, formation, and etiology. Journal of Forensic Sciences 57 (3): 571-7.

Conner, MD, and DT Morgan. 1991. Ceramic assemblage. In The Kuhlman mound group and late woodland mortuary behavior in the Mississippi river valley of west-central Illinois., eds. Karen A. Atwell, Michael D. Conner. Vol. 9, 145. Kampsville, Illinois: Center for American Archaeology.

Cook, DC. 1979. Part four: Subsistence base and health in prehistoric Illinois valley: Evidence from the human skeleton. Medical Anthropology 3 (1): 109-24.

1976. Pathologic States and Disease Process in Illinois Woodland Populations: An Epidemiologic Approach. PhD dissertation, University of Chicago, Chicago, Illinois.

1974. Mortuary practice-assessment of sources of error in paleodemography. American Journal of Physical Anthropology.

Dar, G, Y Masharawi, S Peleg, N Steinberg, H May, B Medlej, N Peled, and I Hershkovitz. 2010. Schmorl's nodes distribution in the human spine and its possible etiology. European Spine Journal 19 (4): 670-5.

Faccia, KJ, and RC Williams. 2008. Schmorl's nodes: Clinical significance and implications for the bioarchaeological record. International Journal of Osteoarchaeology 18 (1): 28-44. 
Garner, C. 1991. Kuhlman demography and disease in comparative perspective. In The Kuhlman mound group and Late Woodland mortuary behavior in the Mississippi river valley of westcentral Illinois., eds. Karen A. Atwell, Michael D. Conner. Vol. 9, 180-207. Kampsville, Illinois: Center for American Archaeology.

Gellhorn, AC, JN Katz, and P Suri. 2013. Osteoarthritis of the spine: The facet joints. Nature Reviews Rheumatology 9 (4): 216.

Goodman, AH, GJ Armelagos, and JC Rose. 1984. The chronological distribution of enamel hypoplasias from prehistoric Dickson mounds populations. American Journal of Physical Anthropology 65 (3): 259-66.

1980. Enamel hypoplasias as indicators of stress in three prehistoric populations from Illinois. Human Biology: 515-28.

Goodman, AH, JW Lallo, GJ Armelagos, and JC Rose. 1984. Health changes at Dickson mounds, Illinois (950-1300 AD). in: Paleopathology at the origins of agriculture.

Hall, RJ. An interpretation of the two-climax model of Illinois prehistory. In Early Native Americans., ed. D. Browman, 401-462. Mouton.

Harn, AD. 1971. The prehistory of Dickson Mounds: A preliminary report. Illinois State Museum.

Hassen, H. 1985. Late Woodland diversity in the fall creek locality, Adams county, Illinois. Wisconsin Archaeology 66 : 282-91.

Herold, EB. 1971. The Indian mounds at Albany, Illinois. Wagners Printers.

Hitzemann, NJ. 1997. Regional osteoarthritis patterns: An examination of Late Woodland trends in west-central Illinois. Northern Illinois University, DeKalb, Illinois. 
Johannessen, S. 1993. Farmers of the Late Woodland. In Foraging and farming in the Eastern Woodlands., ed. CM. Scarry, 57-77. University Press of Florida, Gainesville, Florida.

Johns, J. 2010. A Comparison of Vertebral Osteoarthritis between Archaic and Mississippian Populations and its Relation to Subsistence Activities: An Examination of the Burials at the Perry Site (1LU25) and Moundville (MSM) Sites.

2010. A comparison of vertebral osteoarthritis between archaic and Mississippian populations and its relation to subsistence activities: An examination of the burials at the Perry site (1LU25) and moundville (MSM) sites. Masters., University of Mississippi.

Jurmain, RD, and L Kilgore. 1995. Skeletal evidence of osteoarthritis: A paleopathological perspective. Annals of Rheumatic Diseases 54 (6): 443-50.

Jurmain, RD. 1990. Paleoepidemiology of a central California prehistoric population from CAALA-329: II. degenerative disease. American Journal of Physical Anthropology 83 (1): 83 94.

Lai, P, and NC. Lovell. 1992. Skeletal markers of occupational stress in the fur trade: A case study from a Hudson's Bay company fur trade post. International Journal of Osteoarchaeology 2 (3): 221-34.

Lallo, JW. 1973. The skeletal biology of three prehistoric American Indian societies from Dickson Mounds. PhD Dissertation, University of Massachusetts, Amherst, Massachusetts. Lambert, PM. 2000. Bioarchaeological studies of life in the age of agriculture: A view from the southeast. Tuscaloosa: University Alabama Press.

Larsen, CS. 2002. Bioarchaeology: The lives and lifestyles of past people. Journal of Archaeological Research 10 (2): 119-66. 
1995. Biological changes in human populations with agriculture. Annual Review of Anthropology: 185-213.

Liu, G, M Peacock, O Eilam, G Dorulla, E Braunstein, and CC Johnston. 1997. Effect of osteoarthritis in the lumbar spine and hip on bone mineral density and diagnosis of osteoporosis in elderly men and women. Osteoporosis International 7 (6): 564-9.

Masud, T, S Langley, P Wiltshire, DV Doyle, and TD Spector. 1993. Effect of spinal osteophytosis on bone mineral density measurements in vertebral osteoporosis. BMJ: British Medical Journal 307 (6897): 172-3.

Munoz, SE, DJ Mladenoff, S Schroeder, and JW Williams. 2014. Defining the spatial patterns of historical land use associated with the indigenous societies of eastern North America. Journal of Biogeography 41 (12): 2195-210.

Munson, PJ, PW Parmalee, and RA Yarnell. 1971. Subsistence ecology of Scoville, a terminal Middle Woodland village. American Antiquity 36 (4): 410-31.

Nathan, H. 1962. Osteophytes of the vertebral column: An anatomical study of their development according to age, race, and sex with considerations as to their etiology and significance. Jbjs 44 (2): 243-68.

Nelson, EA, CL Halling, and JE Buikstra. 2016. Investigating fluoride toxicity in a Middle Woodland population from west-central Illinois: A discussion of methods for evaluating the influence of environment and diet in paleopathological analyses. Journal of Archaeological Science: Reports 5 : 664-71.

Nolan, DJ. 1995. Analysis of the woodland feature sample from the FAP 506-rt 96 right-of-way in Adams and Hancock counties, Illinois. Kamspville, Illinois: Center for American Archaeology, . 
Novak, M. 2011. Bioarchaeological analysis of the human skeletal remains from the late mediaeval cemetery of Koprivno, southern Croatia. Bulletin of the International Association for Paleodontology 5 (1): 13-23.

Novak, Mario, and Mario Šlaus. 2011. Vertebral pathologies in two early modern period $\left(16^{\text {th }}\right.$ $19^{\text {th }}$ century) populations from Croatia. American Journal of Physical Anthropology 145 (2): $270-81$.

O'Neill, TW, EV McCloskey, JA Kanis, AK Bhalla, J Reeve, DM Reid, C Todd, AD Woolf, and AJ Silman. 1999. The distribution, determinants, and clinical correlates of vertebral osteophytosis: A population based survey. The Journal of Rheumatology 26 (4) (Apr): 8428.

Perino, GH. 1973. The Late Woodland site component at the Pete Klunk site, Calhoun county, Illinois. In Late woodland site archaeology in Illinois I., ed. J. A. Brown. Urbana: Illinois Archaeological Survey.

1968. Guide to the identification of certain American Indian projectile points: Special bulletin:\# 3. Oklahoma Anthropological Society.

Perino, GH. 1968. The Pete Klunk mound group, Calhoun county, Illinois: The Archaic and Hopewell occupations. Illinois Archaeological Survey Bulletin 6 : 9-124.

Pestle, W, S Demel, M Colvard, and R Pickering. 2007. Skeletal biology and mortuary practice at the Kubinski site (11WI1186), a middle woodland ossuary. Illinois Archaeology: Journal of the Illinois Archaeology Survey 19 .

Plomp, KA, CA Roberts, and US Viðarsdóttir. 2012. Vertebral morphology influences the development of Schmorl's nodes in the lower thoracic vertebrae. American Journal of Physical Anthropology 149 (4): 572-82. 
Resnick, D, and G Niwayama. 1978. Intravertebral disk herniations: Cartilaginous (Schmorl's) nodes. Radiology 126 (1): 57-65.

Riggle, S. 1981. The Late Woodland transition in the central Mississippi valley: AD 7001100. South Dakota Archaeologist 5 : 5-18.

Roberts, CA, and K Manchester. 2005. The archaeology of disease. 3rd ed. Stroud, Gloucestershire: The History Press.

Rose, FR. 2003. A fresh perspective: isotopic evidence for prehistoric human subsistence in the upper Mississippi River valley of west-central Illinois. PhD dissertation, Rutgers, New Brunswick, New Jersey.

Saluja, G, K Fitzpatrick, M Bruce, and J Cross. 1986. Schmorl's nodes (intravertebral herniations of intervertebral disc tissue) in two historic British populations. Journal of Anatomy 145 : $87-96$.

Scarry, CM. 2003. Patterns of wild plant utilization in the prehistoric eastern woodlands. In People and plants in ancient eastern united states., ed. Paul Minnis, 50-104. Washington: Smithsonian Books.

Scarry, CM. 1993. Variability in Mississippian crop production strategies. In Foraging and farming in the eastern woodlands., ed. C. M. Scarry, 78-90. Gainesville, FL: University Press of Florida.

Seidler, A, U Bolm-Audorff, H Heiskel, N Henkel, B Roth-Küver, U Kaiser, R Bickeböller, WJ Willingstorfer, W Beck, and G Elsner. 2001. The role of cumulative physical work load in lumbar spine disease: Risk factors for lumbar osteochondrosis and spondylosis associated with chronic complaints. Occupational and Environmental Medicine 58 (11): 735-46. 
Shore, LR. 1935. On osteoarthritis in the dorsal intervertebral joints a study in morbid anatomy. British Journal of Surgery 22 (88): 833-49.

Simon, ML. 2017. Reevaluating the evidence for middle woodland maize from the holding site. American Antiquity 82 (1): 140-50.

Stafford, CR. 1986. Late woodland chronology and site function. In Early Late Woodland occupations in the fall creek locality of the Mississippi valley., eds. David T. Morgan, C. Russel Stafford, 87-104. Kampsville: Kampsville Archaeological Center.

Struever, S. 1968. Woodland subsistence-settlement systems in the lower Illinois valley. New Perspectives in Archaeology: 285-312.

Tainter, JA. 1975. The Archaeological Study of Social Change: Woodland Systems in WestCentral Illinois.

Tainter, JA. 1977. Woodland social change in west-central Illinois. Midcontinental Journal of Archaeology 2 (1): 67-98.

Üstündağ, H. 2009. Schmorl's nodes in a post-medieval skeletal sample from klostermarienberg, austria. International Journal of Osteoarchaeology 19 (6): 695-710.

Van der Merwe, AE, MY Işcan, and EN L'Abbè. 2006. The pattern of vertebral osteophyte development in a south African population. International Journal of Osteoarchaeology 16 (5): 459-64.

Vandeburg, BJ. 2006. Schmorl's nodes and osteoarthritis in the vertebrae of Middle Woodland skeletal remains from west-central Illinois. Honors in Anthropology., Binghamton University. 
Wagner, AL, FR Murtagh, JA Arrington, and D Stallworth. 2000. Relationship of Schmorl's nodes to vertebral body endplate fractures and acute endplate disk extrusions. American Journal of Neuroradiology 21 (2) (February 01): 276-81.

Waldron, T. 2008. Palaeopathology. Cambridge University Press.

1991. The prevalence of, and the relationship between some spinal diseases in a human skeletal population from London. International Journal of Osteoarchaeology 1 (2): 103-10.

Weiss, E. 2005. Schmorl's nodes: A preliminary investigation. Paleopathology Newsletter 132 . 